\title{
Review
}

Zhifang Zhao*, Tianqi Qi*, Wei Zhou, David Hui, Cong Xiao, Jieyi Qi, Zhihong Zheng, and Zhigang Zhao

\section{A review on the properties, reinforcing effects, and commercialization of nanomaterials for cement-based materials}

https://doi.org/10.1515/ntrev-2020-0023

received February 12, 2020; accepted February 19, 2020

\begin{abstract}
The behavior of cement-based materials is manipulated by chemical and physical processes at the nanolevel. Therefore, the application of nanomaterials in civil engineering to develop nano-modified cement-based materials is a promising research. In recent decades, a large number of researchers have tried to improve the properties of cement-based materials by employing various nanomaterials and to characterize the mechanism of nanostrengthening. In this study, the state of the art progress of nano-modified cement-based materials is systematically reviewed and summarized. First, this study reviews the basic properties and dispersion methods of nanomaterials commonly used in cement-based materials, including carbon nanotubes, carbon nanofibers, graphene, graphene oxide, nano-silica, nano-calcium carbonate, nano-calcium silicate hydrate, etc. Then the research progress on nanoengineered cementitious composites is reviewed from the
\end{abstract}

* Corresponding author: Zhifang Zhao, College of Civil Engineering and Architecture, Zhejiang University of Technology, Hangzhou, 310023, China, e-mail: zhaozhifang7@126.com

* Corresponding author: Tianqi Qi, State Key Laboratory of Water Resources and Hydropower Engineering Science, Wuhan University, Wuhan 430072, China; Center for Advanced Construction Materials, The University of Texas at Arlington, Arlington, TX, 76019, USA, e-mail: tianqi_qi@whu.edu.cn

Wei Zhou: State Key Laboratory of Water Resources and Hydropower Engineering Science, Wuhan University, Wuhan 430072, China

David Hui: Department of Mechanical Engineering, The University of New Orleans, New Orleans, LA, 70148, USA

Cong Xiao, Zhihong Zheng: College of Civil Engineering and Architecture, Zhejiang University of Technology, Hangzhou, 310023, China

Jieyi Qi: China Gezhouba Group Three Gorges Construction Engineering Co., LTD., Yichang, 443000, China

Zhigang Zhao: Communication University of Zhejiang, Hangzhou, 310018, China view of accelerating cement hydration, reinforcing mechanical properties, and improving durability. In addition, the market and applications of nanomaterials for cement-based materials are briefly discussed, and the cost is creatively summarized through market survey. Finally, this study also summarizes the existing problems in current research and provides future perspectives accordingly.

Keywords: nanomaterials, cement-based materials, dispersion method, improvement of properties, commercialization

\section{Introduction}

Nanoscience and nanotechnology are emerging fields of science and technology aiming to understand and to control the matter at the nanoscale level [1]. Nanomaterials can exhibit unusual physical, chemical, and biological behavior. The development of more efficient characterization techniques at the nanoscale has led to an explosion in nanomaterials, in areas such as medicine, environment and energy, chemistry, electronics, civil engineering, and car manufacturing [2-11].

The cement-based materials have been playing a crucial role in infrastructure construction. The production of cement, which is the key component of cementbased materials, is polluting the environment by emitting carbon dioxide. The new or alternative material toward the green and sustainable solution has being pursued all over the world. A better understanding and engineering of nanoscale cement-based materials will definitely deliver a new generation of construction materials with the desired behavior. Cement-based materials are typical random structure composite materials with multi-scale characteristics. By internal composition, these materials can be divided into macro-, meso-, and microscales [12-14]. In the macroscopic scale, 
concrete is considered as a homogeneous material. In the mesoscopic scale, concrete is regarded as a fourphase composite material composed of mortar, coarse aggregate, interfacial transition zone (ITZ) between them, and pore phase $[15,16]$. Similarly, mortar can be further considered as a composite material of cement paste, fine aggregate, ITZ between them, and pore phase. In the microscopic scale, cement paste is mainly composed of unhydrated cement particles, C-S-H, Ca $(\mathrm{OH})_{2}$, ettringite (Aft), other hydrated crystalline products, and pore phase [17]. Among them, the volume of $\mathrm{C}-\mathrm{S}-\mathrm{H}$ in nanoscale accounts for $60-70 \%$ of the cement paste volume. The $\mathrm{C}-\mathrm{S}-\mathrm{H}$ has a vital effect on the mechanical properties and transport properties of cement-based materials [18]. What is the importance of nanotechnology to cementitious materials? It is widely accepted that C-S-H is composed of nanoparticles, and the performance of cement-based materials is controlled by physical and chemical processes occurring at the nanoscale. With enough efforts the nanostructure of $\mathrm{C}-\mathrm{S}-\mathrm{H}$ could be manipulated to improve the properties of cement-based materials $[19,20]$. The basic concept behind nanomodification of materials is that of bottomup engineering, starting with engineered modifications to the molecular structure targeting to affect the bulk behavior of materials. So far, the most effective technical means is adding nanoparticles with different chemical components to the cement-based materials by which the various properties are expected to be optimized. The nanomaterials include carbon nanotubes (CNTs), carbon nanofibers (CNFs), graphene, graphene oxide (GO), nano-silica (nano- $\mathrm{SiO}_{2}$ ), nanocalcium carbonate (nano- $\mathrm{CaCO}_{3}$ ), and nano-calcium silicate hydrate (nano-C-S-H).

This review first focuses on the basic properties of the nanomaterials used in cement-based materials as well as the techniques of nanomaterial dispersion. Then, it presents a state of the art progress of nanomaterials in promoting the early hydration of cement-based materials, enhancing their mechanical properties and improving their durability. The strengthening mechanism of nanocomposites is also clarified. Finally, sustainability will be the main drive for innovation in the near future and therefore we are likely to see an increasing range of nano-engineered cement-based materials and even new nanoparticle types emerging over the coming years. This is a field of very active development, and the current obstacle of high cost and some poor properties of nanomaterial incorporation as the reinforcing materials in the cement composites is likely to be greatly reduced in the future.

\section{The basic properties of nanomaterials used in cement-based materials}

The concept of "nanomaterials" is understood in many different ways in the science community, so there is no clear definition about it [21-23]. However, nanomaterials are generally considered to be natural or artificial materials with one or more sizes at the nanoscale (1-100 nm), larger than atomic clusters but smaller than micro powders; alternatively, structures, agglomerates, or aggregates composed of nano-sized particles or microcrystals, whose sizes may be larger than $100 \mathrm{~nm}$, retain the nanoscale characteristics [24-26]. Some scholars also regarded the materials with a volumespecific surface area of $60 \mathrm{~m}^{2} / \mathrm{cm}^{3}$ or larger as nanomaterials [27]. It has been reported that over 2,000 nanoscale products are available around the world, and more are under development. The nanomaterials currently employed in cement-based materials include CNTs, CNFs, graphene, GO, nano- $\mathrm{SiO}_{2}$, nano- $\mathrm{CaCO}_{3}$, and nano $\mathrm{C}-\mathrm{S}-\mathrm{H}$. The basic properties of the abovementioned nanomaterials are presented as follows.

\subsection{Carbon-based nanomaterials}

New carbon-based nanomaterials can be represented by CNTs, CNFs, graphene, and GO. The CNTs and CNFs are one-dimensional topological nanomaterials, and graphene is a two-dimensional topological nanomaterial; both have more special properties compared to the zerodimensional nanoparticle, especially mechanical properties $[28-30]$.

In 1917, Kohlschutter creatively proposed the concept of GO. In 2004, Novoselov and Geim et al. successfully prepared graphene films using mechanical exfoliation, proved that graphene can exist alone, and elaborated on the basic properties of graphene materials [31]. Graphene is a flat monolayer of carbon atoms and is tightly packed in the honeycomb lattice [32]. The intrinsic strength of graphene is excellent and its theoretical Young's modulus is up to $1 \mathrm{TPa}$, with excellent thermal and electrical properties. The surface area of a single graphene sheet theoretically reaches $2,600 \mathrm{~m}^{2} / \mathrm{g}$ [33-36]. As a graphene derivative, GO has several oxygen-containing functional groups such as hydroxyl, carbonyl, epoxy, and carboxylic groups, rendering Go sheets hydrophilic. Graphene nanosheets 
and their derivatives are usually acquired by mechanical exfoliation, oxidation reduction, Hermer's method, chemical vapour deposition (CVD), or silicon carbide epitaxy [37-40]. The application of GO in cement-based materials is one of the research focuses in recent years. Due to the unique characteristics of GO, such as high specific surface area, surface functionalization, and good dispersion in water, it has good reinforcement effect in different matrix materials. GO was prepared by the Hummers method with graphite powder as a raw material, and different sizes of GO nanoflakes were prepared by the ball milling method [41].

CNTs are man-made one-dimensional carbon crystals with different diameters and chiralities, their radial size is nanoscale, axial size is micro-scale, cross section is concentric circles, and both ends are closed [42]. CNT was first prepared by Iijima in 1991, and its electron micrograph was captured, as shown in Figure 1 [43]. A seamless hollow tube that rolled from single-layered graphite is referred to as single-walled carbon nanotube, and its diameter range is $0.4-2 \mathrm{~nm}$ [44]. Multi-walled carbon nanotube (MWCNT) is a seamless concentric cylinder composed of two- or multi-layer rolled graphene, and its outer diameter range is between several nanometers and a dozen nanometers, the interlayer spacing is about $0.34 \mathrm{~nm}$, and the specific surface area is

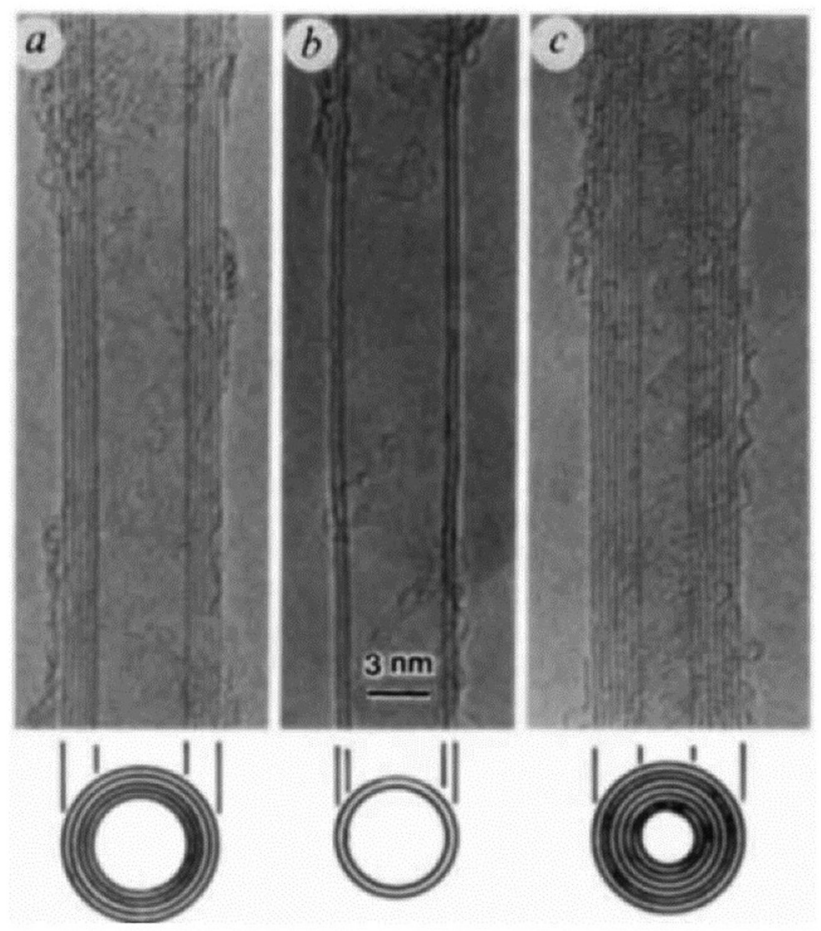

Figure 1: Electron micrographs of microtubules of graphitic carbon. (a) Tube consisting of five graphitic sheets; (b) two-sheet tube, diameter; and (c) seven-sheet tube [43]. generally in the range of $50-1,315 \mathrm{~m}^{2} / \mathrm{g}[45,46]$. Young's modulus of CNT is generally above $1 \mathrm{~TB}$, the tensile strength is $50-200 \mathrm{GPa}$, and the density is about $1.33 \mathrm{~g} / \mathrm{m}^{3}$ [47-50]. CNTs are usually prepared by arc discharge, laser ablation, chemical vapor deposition, gas combustion, solid-phase pyrolysis, glow discharge, and polymerization synthesis methods [51-55].

$\mathrm{CNF}$ is a special carbon fiber, which is usually prepared by the catalytic vapor deposition growth method and electrostatic spinning method. It has ample application prospects in the field of energy conversion and storage and reinforced composite materials [56,57]. The length range of CNFs is generally $50-200 \mathrm{~nm}$, the diameter is $0.5-100 \mathrm{~nm}$, and the aspect ratio is 100-1,000. According to the arrangement of graphene layers, CNFs can be classified into fish-bone CNF, platelet CNF, and tubular CNF, as shown in Figure 2 [58]. CNFs have extraordinary high tensile strength, elastic modulus, electrical conductivity, and thermal conductivity. After heat treatment, their tensile strength and tensile elastic modulus can reach up to $7 \mathrm{GPa}$ and $600 \mathrm{GPa}$, respectively [50].
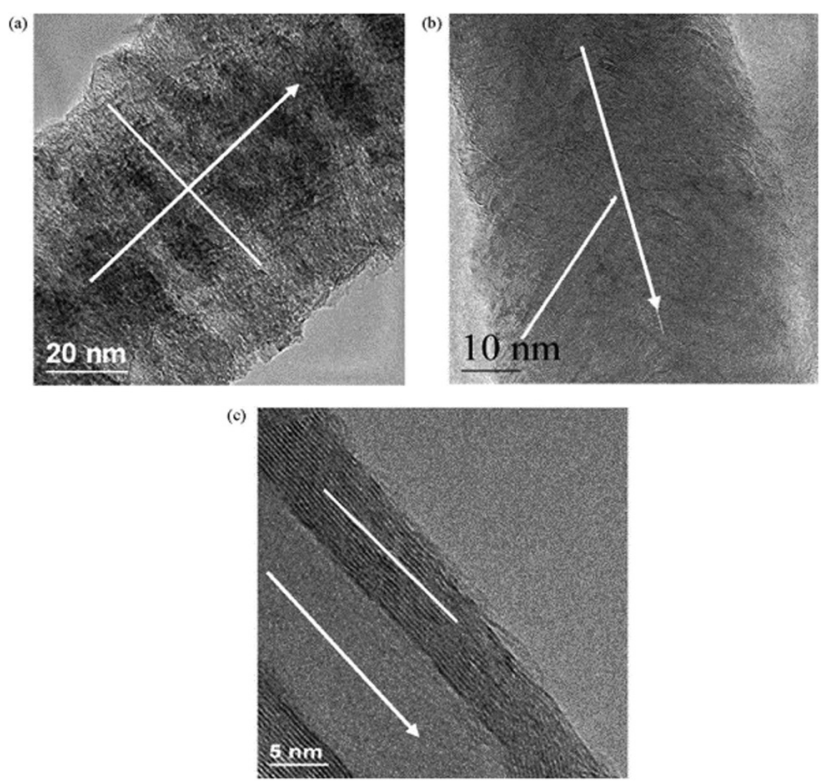

Figure 2: High-resolution transmission electron microscope image of (a) platelet CNF, (b) fish-bone CNF, and (c) tubular CNF [58-60].

\section{2 $\mathrm{Nano}_{-} \mathrm{CaCO}_{3}$ and nano-SiO}

In 1980s, nano- $\mathrm{CaCO}_{3}$, which is an ultra-fine solid powder material, was evolved. The transmission electron microscopy (TEM) graph of nano- $\mathrm{CaCO}_{3}$ is shown in Figure 3 [61]. Due to ultra-fineness of the nano- $\mathrm{CaCO}_{3}$ particles, their crystal structure and surface electron 


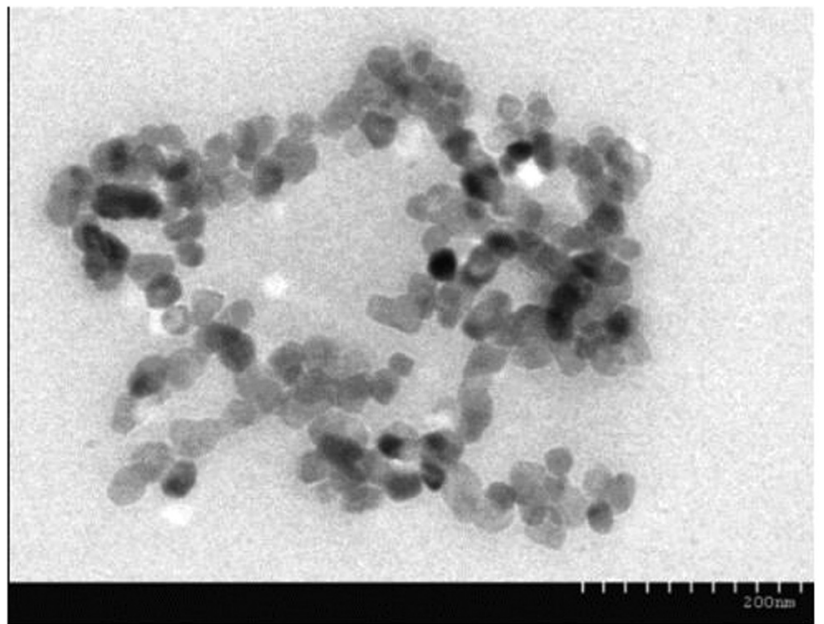

Figure 3: TEM view of nano- $\mathrm{CaCO}_{3}[61]$.

structure are changed, leading to quantum size effect, small size effect, surface effect, and macro quantum effect that are not exhibited in ordinary $\mathrm{CaCO}_{3}$ [62]. The surface structure of calcite crystal of nano- $\mathrm{CaCO}_{3}$ is similar to that of C-S-H, so it has obvious effects of hydration acceleration for cement-based materials. Compared to other nanomaterials, nano- $\mathrm{CaCO}_{3}$ is more affordable. It can be synthesized by the biomimetic synthesis method and carbon dioxide bubbling method [63].

Nano- $\mathrm{SiO}_{2}$, one of the earliest nanomaterials used in cement-based materials, is an amorphous white powder and its microstructure is like a sphere, as shown in Figure 4 $[64,65]$. It has quantum size effect, special optical, and electrical properties and maintains high strength and toughness even under a high temperature. In addition,

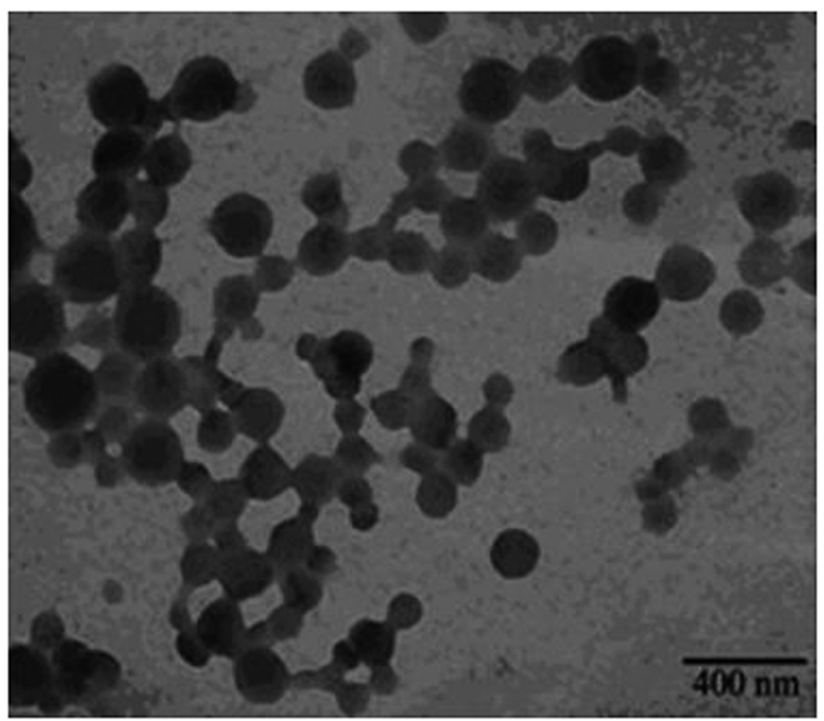

Figure 4: TEM image of nano-silica during gelation [65]. compared to other nanoparticles, nano- $\mathrm{SiO}_{2}$ shows unique advantage in providing increased production of cement hydration $\mathrm{Ca}(\mathrm{OH})_{2}$, possessing faster pozzolanic reactivity, and an accelerating effect on the hydration of cement $[66,67]$. So far, various methods are available for the preparation of nano- $\mathrm{SiO}_{2}$, which can be divided into dry and wet processes. Dry processes include the gas phase method and arc method, and wet processes include precipitation, sol-gel method, microemulsion, and highgravity reaction $[65,68]$.

\subsection{Nano-C-S-H}

Nano-C-S-H particle is a new potential accelerator for cement hydration that has captured extensive attention over the years [69]. The synthetic C-S-H particle has a substantially structural similarity to the C-S-H produced by cement hydration, as shown in Figure 5 [70]. The synthetic C-S-H particle can strongly promote the early hydration of tricalcium silicate, which in turn markedly improves the early strength [70,71]. Although the reaction

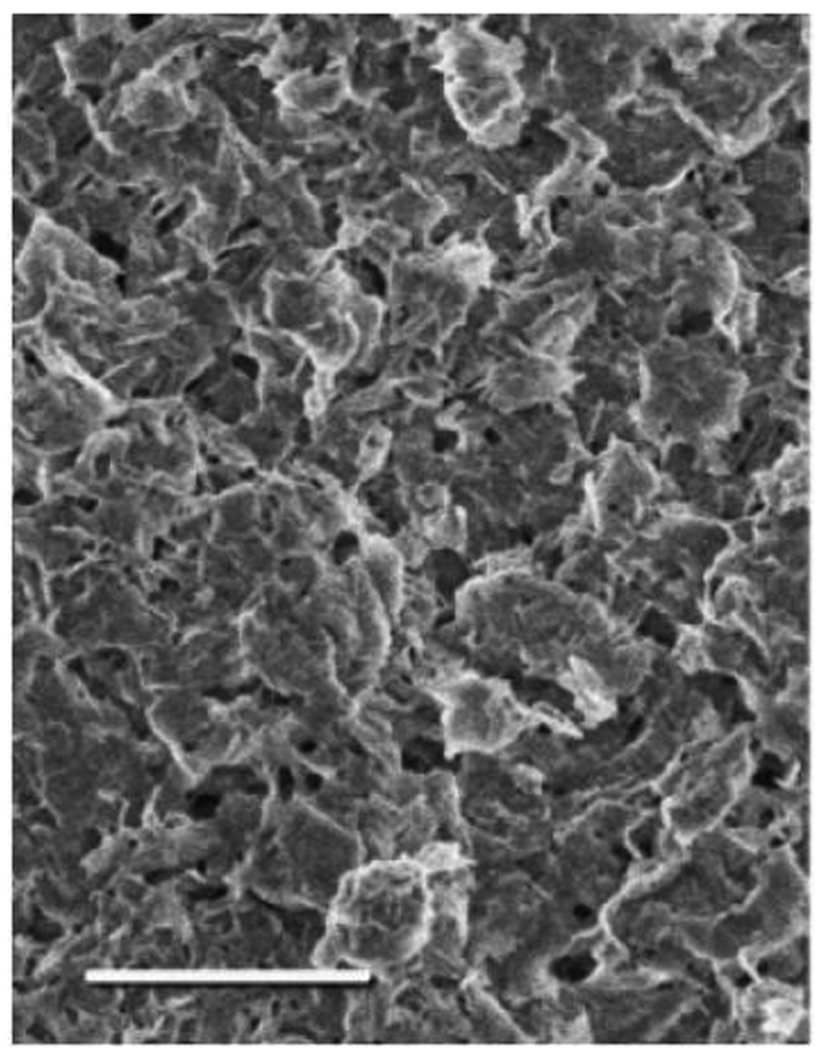

Figure 5: Morphology of the synthetic C-S-H used as a seeding agent during the hydration of $\mathrm{C}_{3} \mathrm{~S}$. The white scale bar indicates $1 \mathrm{~mm}[70]$. 
mechanism remains unclear, the $\mathrm{C} / \mathrm{S}$ ratio of the $\mathrm{C}-\mathrm{S}-\mathrm{H}$ seed seems to be a critical factor to affect the acceleration effect of cement hydration and the mechanical properties of hardened cement paste [72]. Typical nano-C-S-H seeds include xonotlite-type and tobermorite-type C-S-H seeds, mainly synthesized by co-precipitation of calcium salt and silicate or hydrothermal method [69].

\section{Dispersion methods of nanomaterials}

The major challenge associated with the incorporation of nanomaterials in cement-based materials is poor dispersion, which leads to the formation of many defect sites in the nanocomposite, limits the efficiency of the nanomaterials in the matrix, and increases the cost of nanocomposites [73-76]. Incorporation of the nanomaterials, which are not effectively dispersed into the cement matrix, negatively affects the performance of cement-based materials as well as the cement hydration process and later strength development. Thus, good dispersion of nanomaterials is a key step in successful engineering application. So far, the available dispersion methods include physical dispersion, electric field induction, surfactant modification, surface modification, and a combination of several methods.

\subsection{Physical dispersion method}

Physical dispersion method includes mechanical dispersion and ultrasonic dispersion. Mechanical dispersion can input mechanical energy into nanomaterial aggregation by means of high-speed shearing and ultrasound to destroy the bond
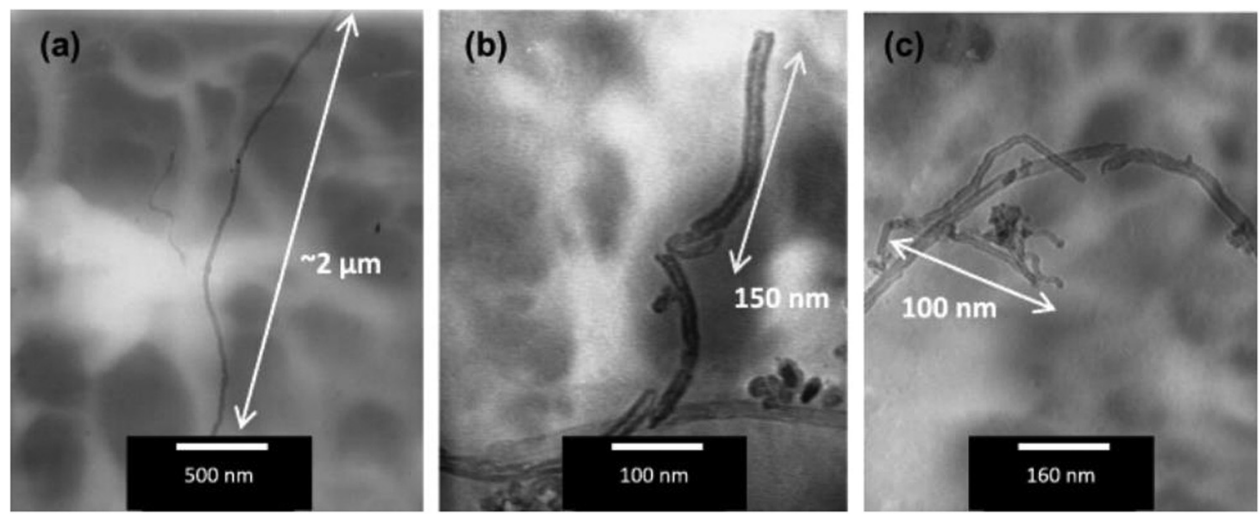

between nanomaterials as much as possible [77-79]. Mechanical agitation is usually employed to disperse particles and powders in liquid, and their dispersion effect may be controlled by the agitation rate, the shape and size of agitator, and the agitation strategy [80]. Electrical voltage is converted to mechanical vibrations in an ultrasonic processor. During the process of cavitation, millions of shock waves are created and high level of energy is released, leading to dispersion of nanomaterials in the liquid. The ultrasonic dispersion method is considered to be an effective dispersion method. However, the dispersion process by only inputting mechanical energy may damage the structure of nanomaterial, for instance, markedly reducing the aspect ratio of CNT $[77,81,82]$. As shown in the TEM image of Figure 6, due to the high entanglement of MWCNTs, the length of a single MWCNT observed before ultrasonic processing is about $2 \mu \mathrm{m}$. After dispersing with high ultrasonic energy $(1,15,000$ and 1,70,000 J), MWCNTs were damaged, and the length of the broken body was about $100-150 \mathrm{~nm}$. In addition, Mendoza et al. [82] found that ultrasonic dispersion has time effect when it was used to disperse CNTs/CNFs, as shown in Figure 7. After $24 \mathrm{~h}$ of standing, the MWCNT/water dispersion is almost completely precipitated. The ultrasonic dispersion method could not ensure homogeneous distribution of nanomaterial in cement. It means that a homogeneous nanomaterial dispersion in water does not guarantee a good dispersion in the nanocomposite as well. It requires the use of various chemical routes in combination with this technique.

\subsection{Surfactant modification method}

Surfactant modification can physically change the surface properties of nanomaterials by adding surfactants,

Figure 6: TEM images of MWCNT after different sonication energies: (a) $0 \mathrm{~J}$, (b) 1,15,000, and (c) 1,70,000 J [82]. 

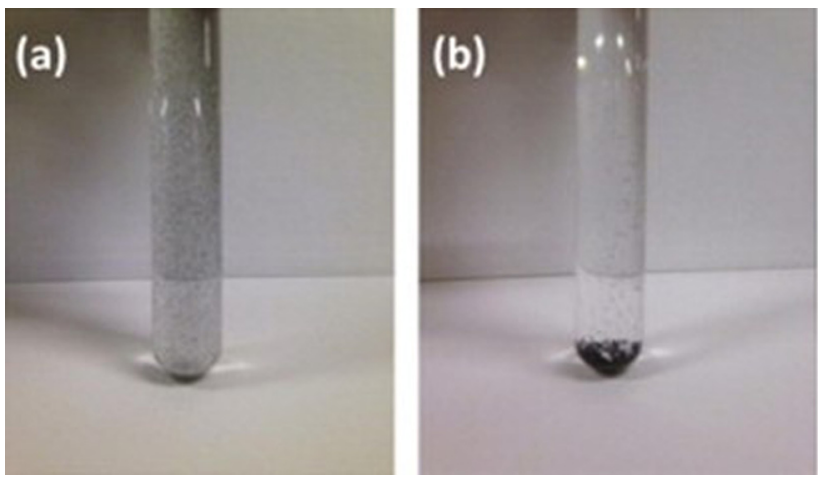

Figure 7: Stability of dispersions of MWCNT/water after (a) $0 \mathrm{~h}$ and (b) $24 \mathrm{~h} \mathrm{[82].}$

which in turn stabilizes their dispersion [83]. For example, this technique neither damages the structure of CNTs nor weakens the mechanical properties and does harm to the electronic structure of CNTs. There are ionic and non-ionic types of surfactants: (1) ionic surfactants can disperse nanomaterials in aqueous solution by hydrophobic/hydrophilic interaction, where the hydrophobic tail is adsorbed on the nanomaterial surface, and the hydrophilic head is bound with water to dissolve; (2) similarly, non-ionic surfactants are based on the adsorption mechanism, their head and tail are disorderly and randomly absorbed on the nanomaterial surface to maintain the system stability [84-90]. The possible morphologies of the absorbed amphiphilic molecules on SWNTs are shown in Figure 8 [91]. Surfactant modification is user-friendly, but the cost of dispersant and its connectivity of nanomaterials within the cementitious matrix should be considered.

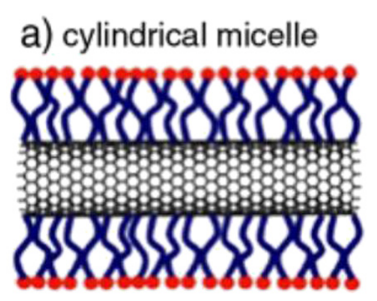

b) hemimicelle

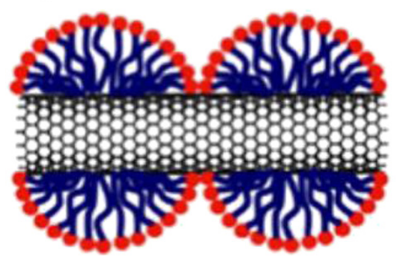

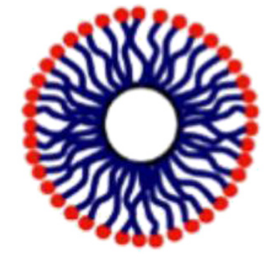

c) random adsorption

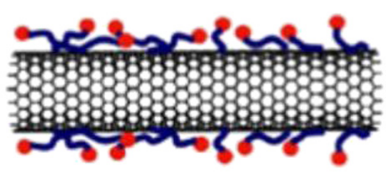

Figure 8: Schematic illustration of various surfactant assembly structures on a SWNT, including (a) cylindrical micelles, (b) hemimicelle, and (c) random adsorption [91].

\subsection{Covalent functionalization method}

Covalent chemical modification is the most common approach to improve the dispersion of nanomaterials in water. This technique can be used to covalently graft with functional groups that can combine with nanomaterials by the covalent bond and then exhibit modification effect. However, it involves additional chemical reagent, complex synthesis, and post-processing procedures and consequently results in higher cost [92]. For silicon-based materials, such as silicon dioxide, Chen et al. [93] grafted methacryloxypropyltrimethoxysilane onto the surface of nano- $\mathrm{SiO}_{2}$ particles to improve their dispersity in acrylic resins. $\mathrm{Gu}$ et al. [94] synthesized the core-shell nanoparticles of nano- $\mathrm{SiO}_{2}$ polycarboxylate (PCE) superplasticizer with high dispersity by using silylated PCE superplasticizer and colloidal nano- $\mathrm{SiO}_{2}$ as raw materials, and its schematic diagram is shown in Figure 9. Plasma process is also considered to be an effective way for the improvement of dispersity of CNTs. This technique increases the surface charge density of CNTs and obtained a higher zeta potential of the treated CNTs. The strong repulsion force between the treated CNTs uniformly disperse them in the aqueous solution. Also, this treatment can change the hydrophobic nature of CNTs on which the surface functional groups form. It can stabilize the dispersed treated CNT solution for a long time without sedimentation [95]. Currently, there is research progress on covalent modification of nano- $\mathrm{SiO}_{2}$ and nano- $\mathrm{TiO}_{2}$ to improve the hydrophobicity of coated concrete [96]. Li et al. [96] found that nano-SiO ${ }_{2}$ and nano$\mathrm{TiO}_{2}$ can be modified effectively from hydrophilicity into hydrophobicity by a silane coupling agent, thereby guaranteeing the dispersion stability of nanoparticles within organic film coatings.

\subsection{Cement admixture modification method}

The most common admixture used for dispersing nanomaterials such as CNTs in the cement matrix is polycarboxylic acid-based (COOH) superplasticizer [97-99]. The use of PCE led to a very good dispersion of MWCNT in water as well as in the hardened cement paste. Li et al. [100,101] employed the mixed solution of $\mathrm{H}_{2} \mathrm{SO}_{4}$ and $\mathrm{HNO}_{3}$ to produce the carboxylic acid group on the surfaces of CNTs. The chemical reactions take place between the carboxylic acid and the hydration products $\mathrm{C}-\mathrm{S}-\mathrm{H}$ or $\mathrm{Ca}(\mathrm{OH})_{2}$. The interaction results in a strong covalent force on the interface between CNTs and the composite matrix to increase the compressive and bending strength of the nanocomposites. 


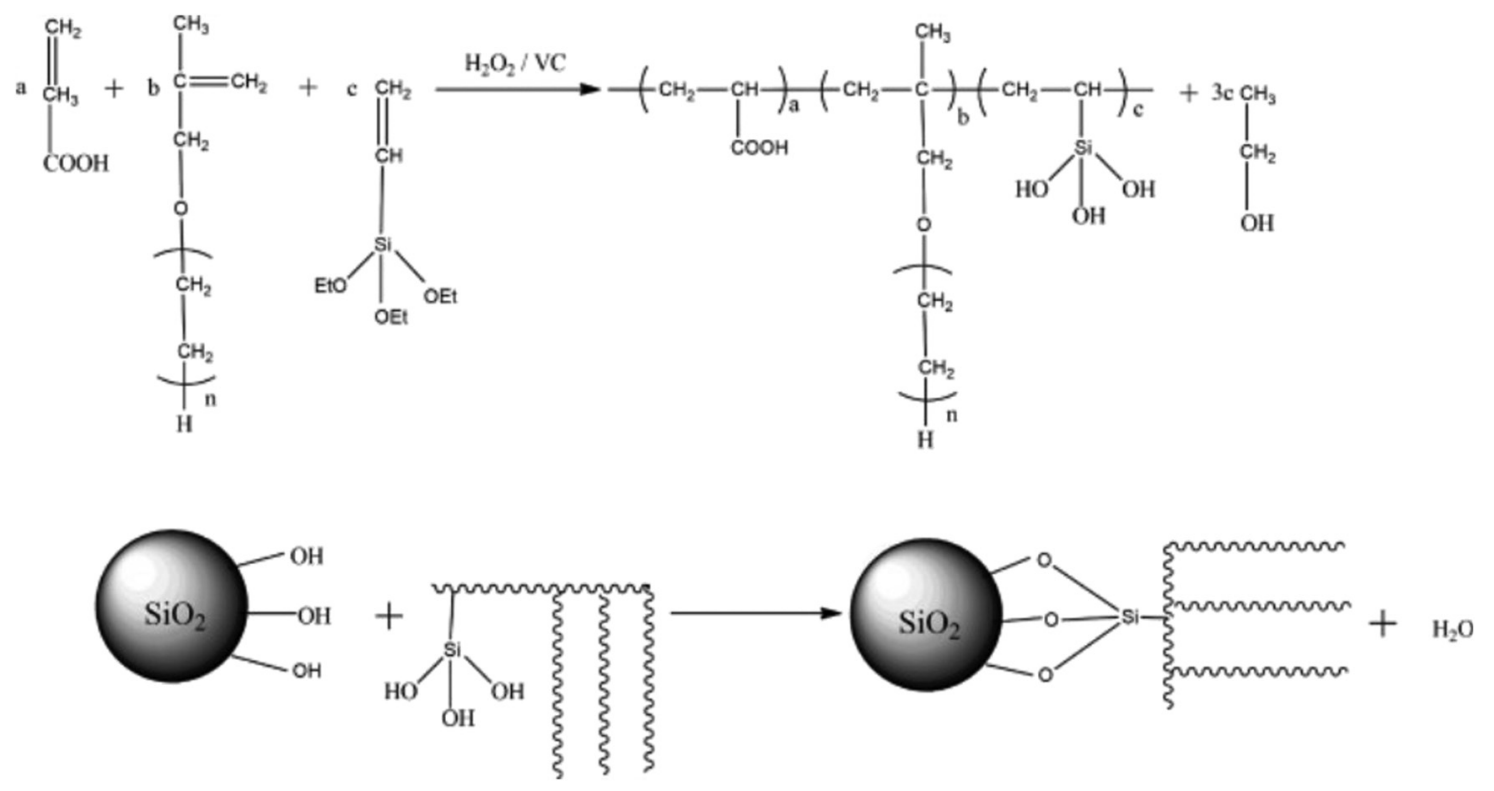

Figure 9: Schematic representation for ideal synthesis of $\mathrm{SiO}_{2} @ \mathrm{PCE}[94]$.

\subsection{Electric field induction method}

Electric field induction is a special method for dispersing CNTs/CNFs, which are incorporated into organic solvent to form thin solution layer with a small cross-section area; and metal mesh piece or metal foil is embedded into the thin layer as a two-terminal electrode. A direct current or an alternating current is imposed on the electrode so as to electrically polarize the CNTs/CNFs and make them electric dipoles. Under the action of electric field, CNTs/CNFs will generate regular movements and tend to be distributed along the electric field line, which in turn cause their uniform dispersion $[50,102]$. The referenced schematic diagram is shown in Figure 10 [102].

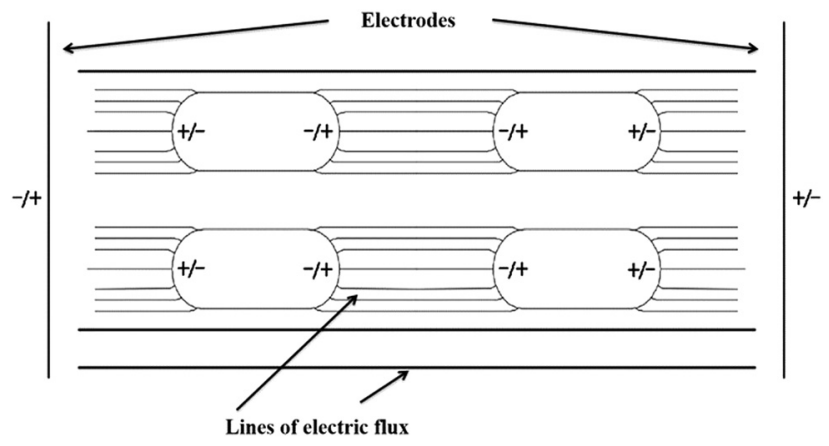

Figure 10: Schematic illustration of the interaction between aligned and polarized cylindrical particles in an electric field [102].

\section{Enhancement effects of nanomaterials on properties of cement-based materials}

\subsection{Acceleration of hydration}

The strength development of cement-based materials depends on their hydration process which is controlled by chemical reactions and physical changes [103]. The acceleration of cement hydration at early age can effectively improve the strength of cement-based materials at early age, improve construction efficiency, reduce maintenance cost, and meet the requirements for rapid construction in particular environment $[104,105]$. The capability of nanomaterials to accelerate cement hydration is derived from their nanoscale size and high specific surface area. The high specific surface area of nanomaterials leads to a substantial increase in available nucleation sites of hydration products in a cement paste, which in turn makes the effect of nucleation of hydration products much stronger than that of any usual mineral admixtures. The size of nanomaterials also enables them to effectively enter the gaps between cement particles. This bridge effect is helpful for hydration products contacting to form networks earlier [106,107].

It was shown that nano- $\mathrm{SiO}_{2}$, nano- $\mathrm{CaCO}_{3}$, and nano-C-S-H can effectively promote the hydration of cement. Björnström et al. [108] reported the hydration 
acceleration effect of nano- $\mathrm{SiO}_{2}$ for cement is contributed by surface $\mathrm{Q}^{2-3} \mathrm{Si}-\mathrm{OH}$ groups. Qing et al. [109] compared the influence of nano- $\mathrm{SiO}_{2}$ and silica fume on consistency and setting time of cement paste. The results show that the nano- $\mathrm{SiO}_{2}$ made the cement paste thicker and the setting process faster. Lin et al. [110] reported that nano- $\mathrm{SiO}_{2}$ increased the crystals of cement hydration, resulting in improved effects of sludge/fly ash on the hydration of mortar as well as on the early strength development. The scanning electron microscopy (SEM) images are shown in Figure 11. Kong et al. [111] suggested that addition of colloidal silica sol with mono-dispersed nanoparticles exhibited a more significant accelerating effect on cement hydration than that of nano- $\mathrm{SiO}_{2}$ with agglomerates in the microscale. The acceleration may have nothing to do with the seeding effect, but highly depends on the rapid depletion of calcium ions in the paste. Wang et al. [112] incorporated nano- $\mathrm{SiO}_{2}$ particles with an average particle size of about $20 \mathrm{~nm}$ into the cement paste to conduct experiments. It was found that with the addition of nano- $\mathrm{SiO}_{2}$, the exothermic peak of cement hydration heat increased obviously. The exothermic peak appearance time was advanced. The thermogravimetry-differential scanning calorimetry results also confirmed that nano- $\mathrm{SiO}_{2}$ promoted the formation of C-S-H gel. A recent study also revealed that nano- $\mathrm{SiO}_{2}$ can cause pozzolanic reaction of silica with the $\mathrm{Ca}(\mathrm{OH})_{2}$, which forms more C-S-H gels in the cement system [113].

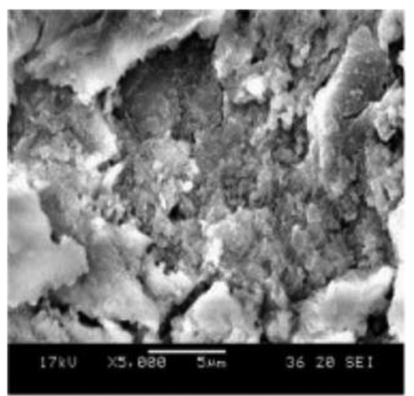

(a)

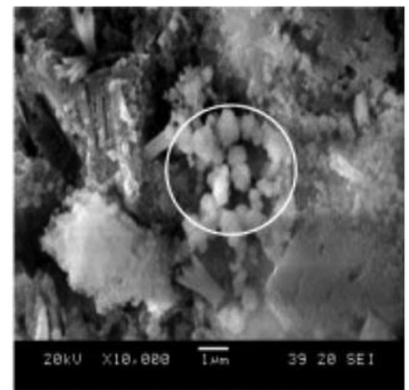

(b)
Figure 11: Microstructures for the specimens with (a) $0 \%$ and (b) $1 \%$ of nano- $\mathrm{SiO}_{2}$ added when cured for $7 \mathrm{~d}$ [110].

Sato and Beaudoin [114] reported that the hydration of Portland cement paste containing high-content ground granulated blast-furnace slag (GGBFS) is obviously accelerated by the nano- $\mathrm{CaCO}_{3}$ addition, which compensates for the delayed hydration process to the cement systems containing high-content GGBFS. Later, Sato and Diallo [115] further studied the mechanism how the nano- $\mathrm{CaCO}_{3}$ promoted the cement hydration by comparing the effect of nano- $\mathrm{CaCO}_{3}$ and micro- $\mathrm{CaCO}_{3}$. The results show that the addition of nano- $\mathrm{CaCO}_{3}$ had an accelerating effect on the hydration of $\mathrm{C}_{3} \mathrm{~S}$ as well as on the hydration of ordinary portland cement (OPC) and shortened the induction period of $\mathrm{C}_{3} \mathrm{~S}$ hydration, as shown in Figure 12.

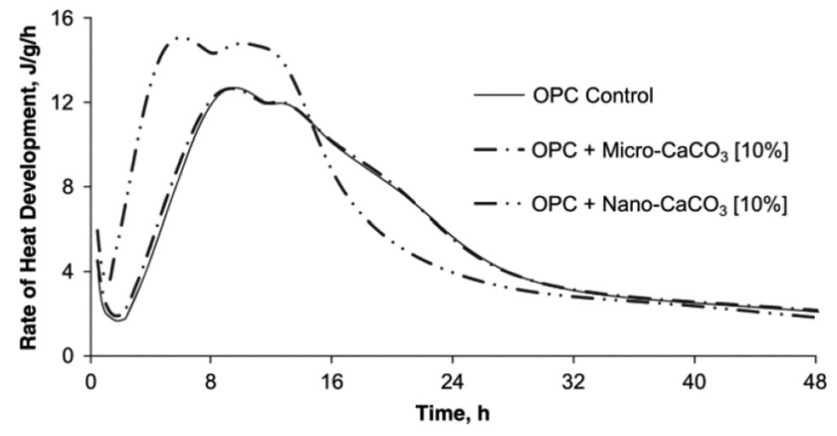

Figure 12: Conduction calorimetry results for OPC control and OPC with the addition of $10 \%$ micro- $\mathrm{CaCO}_{3}$ and nano- $\mathrm{CaCO}_{3}$ [115].

Qian et al. [116] found that the hydration degree of fly ash can be increased for the fly ash concrete with the addition of nano- $\mathrm{CaCO}_{3}$ by the SEM observation. Liu et al. [117] found that the flowability decreased and the setting time of fresh cement paste was shortened with the increase in nano- $\mathrm{CaCO}_{3}$ volume. Other studies confirmed that the addition of nano- $\mathrm{CaCO}_{3}$ greatly accelerated the setting and hardening process of ultrahigh performance concrete (UHPC). The nano- $\mathrm{CaCO}_{3} \mathrm{can}$ be considered as a setting and hardening accelerator [118]. Meng et al. [119] examined the effect of nano$\mathrm{CaCO}_{3}$ slurry on the hydration of concrete with and without fly ash and proposed an idea of using nano$\mathrm{CaCO}_{3}$ with fly ash as a composite nanomaterial to promote the hydration of cement at early ages and that of fly ash at late ages. This may be helpful for the application of nanomaterials in concrete. Yang et al. [120] discussed the mechanism of the influence of nano$\mathrm{CaCO}_{3}$ on the strength of a high-volume fly ash mortar (HVFAM). The results showed that by increasing the nucleation sites, nano- $\mathrm{CaCO}_{3}$ led to more rapid growth of hydration products, thus improving the strength of the HVFAM. Nano-C-S-H gel is a new type of nanomaterial developed in recent years, and it was reported that the synthetic C-S-H can significantly promote the hydration of $C_{3} S$ in cement $[70,71,121]$. As shown in Figure 13, the presence of synthetic C-S-H leads to significant differences in the appearance of $\mathrm{C}_{3} \mathrm{~S}$ particles during hydration. It indicates that $\mathrm{C}_{3} \mathrm{~S}$ is obviously dissolved during the preinduction period, which is identical to the intense release of hydration heat in this period for the seed system [70]. 
Alizadeh et al. [70] found that the properties of the resulting C-S-H hydration products are likely to depend on the lime-to-silica $(\mathrm{C} / \mathrm{S})$ ratio of the synthetic C-S-H. By the addition of selective C-S-H seeds, the nanostructure of the hydration products of the Portland cement may be tailored for optimum engineering and durability performance.

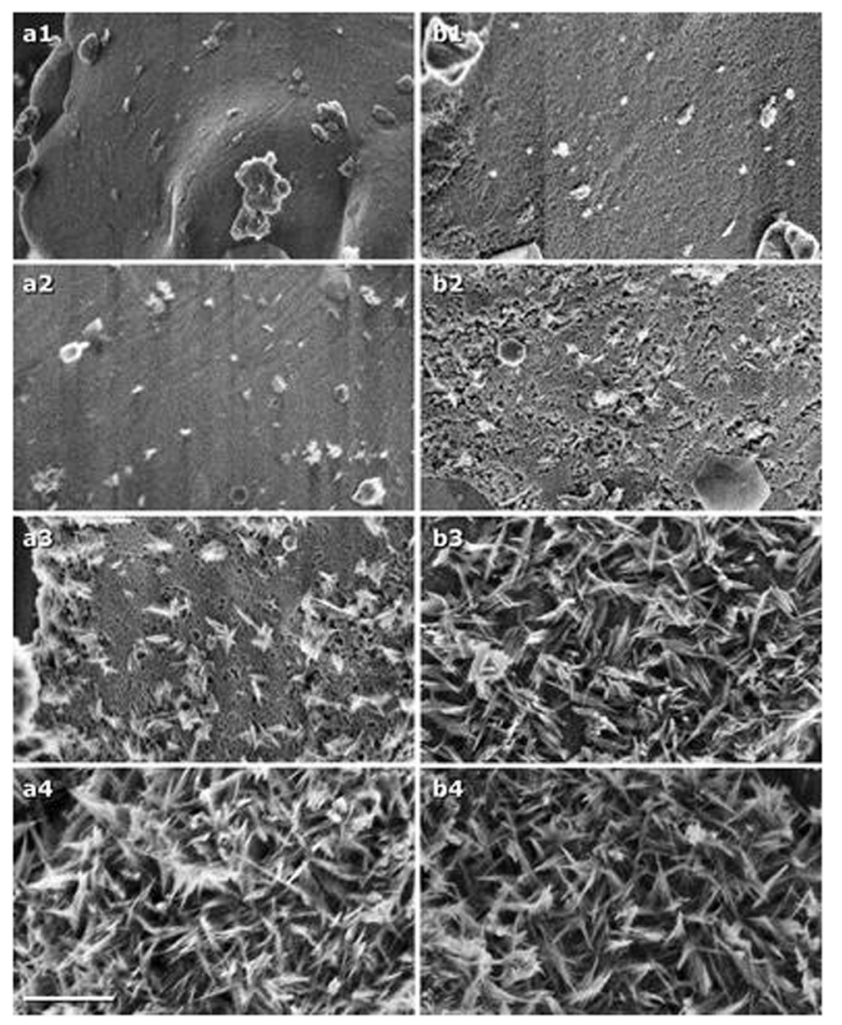

Figure 13: SEM micrographs of the evolution of the surface of $\mathrm{C}_{3} \mathrm{~S}$ at various hydration times. Series (a) (control sample): a1: $20 \mathrm{~min}$; a2: $1 \mathrm{~h} 20 \mathrm{~min} ; \mathrm{a3:} 2 \mathrm{~h} 30 \mathrm{~min}$; and a4: $7 \mathrm{~h}$. Series (b) $\left(\mathrm{C}_{3} \mathrm{~S}\right.$ in the presence of synthetic C-S-H [C/S = 0.8]): b1: $10 \mathrm{~min} ; \mathrm{b} 2: 1 \mathrm{~h}$; b3: $3 \mathrm{~h}$; and b4: $10 \mathrm{~h}$. The white scale bar indicates $500 \mathrm{~nm}$ [70].

Nicoleau [122] found that a small amount of nanoscaled C-S-H particles $(0.3 \%)$ improved the strength of the mortar at $10 \mathrm{~h}$ and $1 \mathrm{~d}$ by up to $303 \%$ and $56 \%$. In addition, they also employed the comb-like copolymers to achieve stable suspensions of low-density aggregates of C-S-H particles, which constitute an innovative hardening accelerator for cementitious systems. The more loosely packed the C-S-H aggregates, the more efficient the C-S-H is taken as a seeding material [105]. Long et al. [123] suggested that the nano-C-S-H improved the nucleation rate and growth rate, and the improvement degree of the nucleation rate is much higher than that of the growth rate.

However, whether CNTs/CNFs can accelerate the hydration process is uncertain. Based on the measurement results of Vickers hardness, Makar et al. [124] found that CNTs affected the early hydration process and produced higher hydration rates than those experienced by the blank specimens through the Vickers hardness test. They found, in a further study, that CNTs can accelerate the hydration reaction of $\mathrm{C}_{3} \mathrm{~S}$ in ordinary Portland cement and influence the morphology of both the initial hydration products of $\mathrm{C}_{3} \mathrm{~A}$ and $\mathrm{C}_{3} \mathrm{~S}$ [125]. Cui et al. [126] measured the hydration heat of composite materials with different CNT contents in the first $48 \mathrm{~h}$ and found that the incorporation of CNTs in cementbased materials can accelerate the cement hydration reaction. Zhao et al. [127] found that the initial and final setting time of cement paste incorporating CNTs become shorter with increasing volume of CNTs in the nanocomposite. The researchers argued that whether or not the addition of CNTs/CNFs can accelerate the hydration of cement-based materials. Amin et al. [128] revealed that the presence of CNTs had no effect on the hydration process of the pure Portland cement or Homra (clay bricks waste)/ ordinary Portland cement blend composite by the observations of X-ray diffraction (XRD), differential scanning calorimetry, and SEM tests. Shi et al. [129] employed Fourier transform infrared spectroscopy to characterize the earlyage hydration process of CNTs/cement composites. The results showed that the shifting speed of the characteristic peak for the blank specimen was the same as that for the specimen enhanced with CNTs, which indicated that incorporating CNTs into the Portland cement had no effect on the early age hydration reaction.

\subsection{Optimization of mechanical properties}

Mechanical properties are the basic properties of cement-based materials, which can finally determine the bearing capacity, service life, and safety of a structure. Therefore, many researchers concentrate on how to improve the mechanical properties of cementbased materials. The mechanical properties of cementbased materials mainly depend on their microstructure. At the microscopic level, the cement paste matrix is a porous material composed of $\mathrm{Ca}(\mathrm{OH})_{2}$, aluminate, unhydrated cement, and amorphous nanostructure hydration product C-S-H [130]. Related studies reveal that the mechanical behavior of cement-based materials strongly depend on nano-size dimensions of solid materials such as C-S-H gel or voids such as the gel porosity in the cement matrix and the ITZ between cement paste and aggregate particles [131]. By now, nanomaterials that can significantly reinforce the 
mechanical properties of cement-based materials include nanomaterials with pozzolanic activity and carbon-based nanomaterials.

Previous studies proved that nano- $\mathrm{SiO}_{2}$ can be used as a nanofiller to fill the gaps between $\mathrm{C}-\mathrm{S}$ - $\mathrm{H}$ gel particles, which in turn improved the strength and toughness of the polymer composite [132]. As a typical pozzolanic material, nano- $\mathrm{SiO}_{2}$ not only improves the microstructure of cement mortar as a filler but also increases the content of $\mathrm{C}-\mathrm{S}-\mathrm{H}$ by the pozzolanic reaction with calcium hydroxide [133-136]. Moreover, compared with the traditional pozzolanic active supplementary material, nano- $\mathrm{SiO}_{2}$ can be more uniformly dispersed in the cementitious system due to small size, large specific surface area, and high activity. Li [136] conducted tests of pozzolanic activity and hydration heat of the highvolume fly ash high-strength concrete incorporating nano- $\mathrm{SiO}_{2}$ (SHFAC) and confirmed that the pozzolanic activity of the high-content fly ash cementitious system significantly improved after incorporating a small amount of nano- $\mathrm{SiO}_{2}$. In addition, the results of the mechanical property tests also proved that the shortand long-term strength of the SHFAC increased, and the test results are given in Figure 14, in which PCC means the reference concrete and HFAC means high-volume fly ash high-strength concrete.

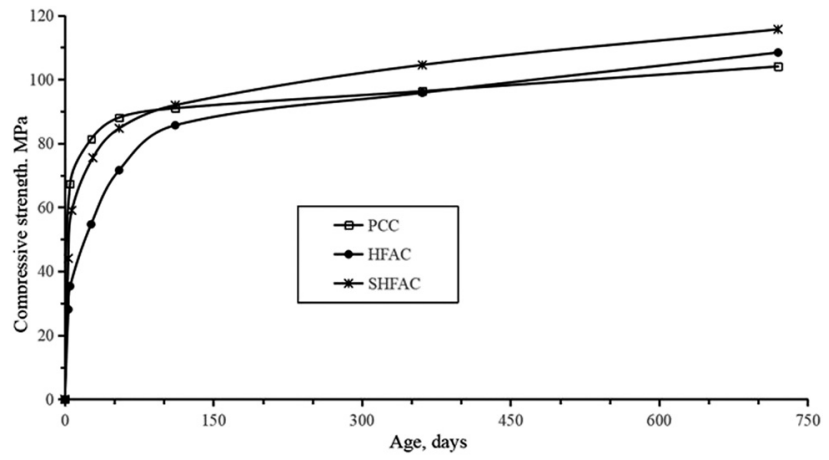

Figure 14: Development of the compressive strength versus age [136].

Qing et al. [109] compared the effects of nano- $\mathrm{SiO}_{2}$ and silica fume on the strength of hardened cement paste and found that the strengths incorporating nano- $\mathrm{SiO}_{2}$ were significantly higher than those incorporating silica fume especially at $3 \mathrm{~d}$. The nano- $\mathrm{SiO}_{2}$ composite can consume more $\mathrm{Ca}(\mathrm{OH})_{2}$ at the interface of paste-aggregate and can improve the interface structure more effectively than the silica fume composite by the XRD observation. Givi et al. [137] also reported that after incorporating $2 \%$ of nano- $\mathrm{SiO}_{2}$, the compressive strength, splitting tensile strength, and flexural strength of the concrete improved at all ages. Pourjavadi et al. [138] found that at $7 \mathrm{~d}$ and $28 \mathrm{~d}$, the compressive strength of incorporating nano- $\mathrm{SiO}_{2}$ concrete improved by $23-38 \%$ and $7-14 \%$, respectively, and the flexural strength improved by $7-10 \%$ and $3-11 \%$ as well. Garg et al. [139] studied the effects of incorporating micro-silica with optimized content of nano- $\mathrm{SiO}_{2}$ on the improvement of cement mortar strength, and the results showed that the compressive strength improvement rate of blending the two $\mathrm{SiO}_{2}$ materials was about three times of that with incorporation of single nano- $\mathrm{SiO}_{2}$. Nazerigivi et al. [140] examined the influences of combination of nano- $\mathrm{SiO}_{2}$ of two different sizes $(15$ and $80 \mathrm{~nm})$ on the mechanical behavior of ternary blended concrete. The findings showed that the ternary blended concrete achieved a significant improvement of compressive, flexural, and tensile strength at all curing ages.

Findings [50,106,141] show that the reinforcing mechanism of CNTs/CNFs in cementitious composites mainly include the following: (1) filling effect, (2) nucleation effect, and (3) bridging effect. In cementbased materials, the fully dispersed and stretched CNTs/ CNFs can act as a fiber skeleton to bridge C-S-H gels and micro-cracks, thereby inhibiting the initiation and extension of cracks, as shown in Figure 15. In 2005, Li et al. [100] incorporated CNTs and CNFs in cement composites and compared their reinforcing effects. The results showed that the compressive strength and bending strength of the cement composite with the addition of CNTs improved up to $19 \%$ and $25 \%$, respectively. However, the compressive strength of the

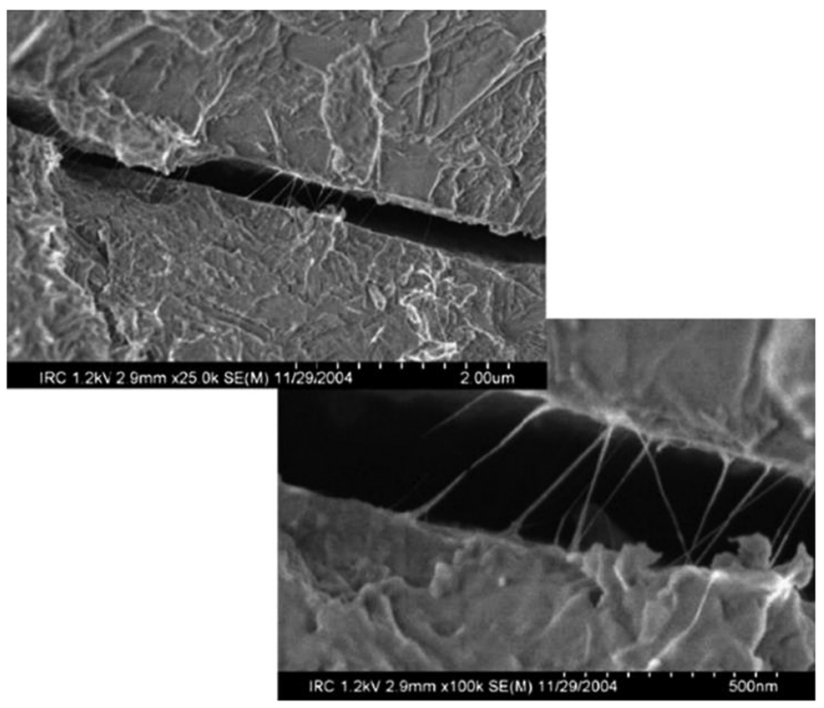

Figure 15: Microscope image of CNTs' bridge in cement crack [50]. 
cement composite with the addition of CNFs reduced, which in turn demonstrated that the reinforcing effect of CNTs is much better than that of CNFs. Afterward, further test studies also confirmed that CNTs can improve the compressive strength and flexural strength of cement-based materials at different levels [142-145]. Wang et al. [143] employed gum arabic as a dispersant to prepare a stable homogeneous suspension of MWCNTs by which the flexural strength of the CNT-reinforced composite improved to $43.38 \%$. Konsta-Gdoutos et al. [49] compared the reinforcing effects of CNTs with different lengths in cement-based materials. It is confirmed that longer CNTs have a better reinforcing effect than the shorter ones, and only $60 \%$ dosage was required to achieve the same level of mechanical performance for the nanocomposite. CNFs also significantly increased the strength of cement-based composites. Metaxa et al. [146] used ultra-high resolution field emission SEM to investigate the influences of CNFs on bending strength and nanostructure of cement-based composites. Nanoscale SEM imaging results show that CNFs can control cracking by bridging nanocracks and pores and form good bonding between the CNFs and the hydration products of cement. The results of flexural test are given in Figure 16, and CNFs significantly improved the flexural strength of the matrix. A very low addition $(0.048 \mathrm{wt} \%)$ was suggested as an optimal concentration of CNFs to achieve the maximum flexural strength reinforcement for the nanocomposites.

Galao et al. [147] found that when the CNF dosage was within $0.00-2.00 \mathrm{wt} \%$, an increase of $5.3 \%$ of the compressive strength can be achieved for every $1 \%$ of CNFs added to the cement mortar. Lv [148,149] studied the toughening effect and mechanism of GO nanosheets in cement-based composite materials. They found that, with only about $0.03 \mathrm{wt} \%$ of GO incorporated, the compressive strength and flexural strength of the nanocomposite at $28 \mathrm{~d}$ were $38.9 \%$ and $60.7 \%$ higher than those of the cement paste without GO, respectively [149].

Besides strength, elastic modulus is another critical index for evaluating the mechanical properties of materials. Saez de Ibarra et al. [97] measured the microhardness and Young's modulus of the cement pastes with the addition of CNTs by the nanoindentation test with a sharp diamond three-sided pyramidal tip mounted on an atomic force microscope (AFM) probe and reported the enhancement in Young's modulus when the CNTs were well dispersed into the cement paste. Shah et al. [150] examined the reinforcing effect of CNTs in the cement matrix $(\mathrm{w} / \mathrm{c}=0.5)$ and found that Young's modulus of the nanocomposites at $28 \mathrm{~d}$ increased by 50\% compared to that of the plain cement paste. Konsta-Gdoutos et al. [49] presented the probability distributions of Young's modulus of the CNT-reinforced cement sample by the nanoindentation experiment, as shown in Figure 17. Findings show that the increase in Young's modulus can be attributed to the increase in high-stiffness C-S-H after incorporating CNTs into the cement paste.

Moreover, a few studies by Konsta-Gdoutos and Danoglidis et al. [151-153] reported that the addition of a very low amount of $0.1 \mathrm{wt} \%$ CNTs to the plain mortar increased about 2.0 times the Young modulus. In a recent study, Konsta-Gdoutos et al. [154] used a very low amount of $0.1 \mathrm{wt} \%$ CNTs to reinforce the concrete successfully, without changing the mix proportion, the amount, and type of aggregates. It resulted in the nanomodified concrete exhibiting about 1.6 times higher modulus value based on the uniaxial compression test and bending test.

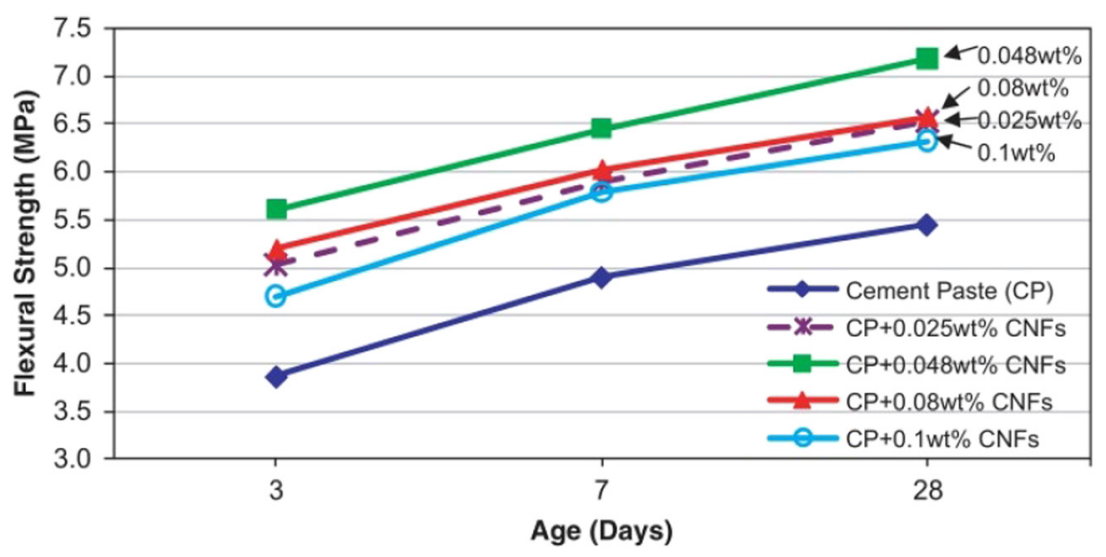

Figure 16: Effect of CNF concentration on flexural strength of cement paste [146]. 


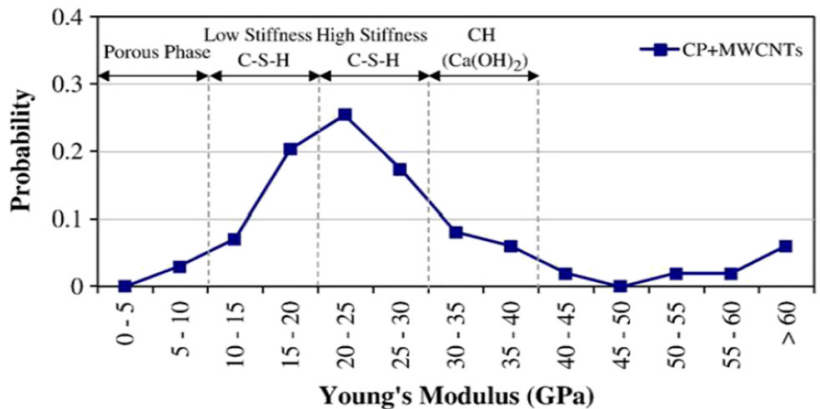

Figure 17: Probability plot of Young's modulus of 28-day cement paste and cement paste reinforced with $0.08 \mathrm{wt} \%$ short MWCNTs $(w / c=0.5)[49]$.

\subsection{Improvement of durability}

The durability of cementitious materials is under the influence of multiple factors, among which the most crucial factors are the porosity and pore characteristics of the cement matrix. The durability enhancement of cement-based materials by nanomaterials exhibits in the following two aspects: permeability resistance and corrosion resistance [155]. For the cement-based materials, the permeability resistance and corrosion resistance are closely associated with the compactness and pore shape and distribution of the cement matrix. The pores $(>20 \mathrm{~nm})$ in cement-based materials usually become the channels through which external moisture and aggressive chemicals diffuse [106]. The size of nanomaterials enables them to fill the $20-150 \mathrm{~nm}$ pores in concrete under effective dispersion. This filling effect for micropores can make the cement matrix phase and the ITZ denser and optimize the distribution of pores, which in turn enhances the permeability and corrosion resistance of the cementitious materials.

Compared to zero-dimensional nanoparticles, carbon-based nanomaterials have better behavior due to their high-dimensional topology. Chaipanich et al. [156] observed the microstructures of CNT-fly ash composites with low and high CNT concentrations by SEM. Findings show that good interaction between CNTs and the fly ash cement matrix is attributed to CNTs acting as a filler leading to denser microstructures of the cementitious matrix. Zdravkov et al. [157] suggested that CNTs can help to effectively reduce the amount of pores less than $50 \mathrm{~nm}$ in the cement matrix. Zhang and Li [158] compared the effects of nano- $\mathrm{SiO}_{2}$ and nano- $\mathrm{TiO}_{2}$ on the improvement of resistance to chloride penetration of concrete for pavement. It was found that the pore structure and resistance to chloride penetration of concrete incorporating nano- $\mathrm{TiO}_{2}$ are superior to those of concrete incorporating the same amount of nano- $\mathrm{SiO}_{2}$. The CNTs had a higher unit incorporation efficiency. Currently, there is another finding on the application of nano- $\mathrm{SiO}_{2}$ to enhance the long-term durability of autoclaved concrete [159]. It was found that nano- $\mathrm{SiO}_{2}$ replacement at $1-3 \%$ by weight of cement can effectively improve the short- and long-term carbonation and chloride resistance of the autoclaved concrete, especially long-term performance.

Wang et al. [160,161] employed field emission scanning electron microscopy, energy dispersive spectroscopy, and mercury intrusion porosimetry to characterize the microstructure and microscopic behavior of $\mathrm{CNF} /$ cement composites. The results show that incorporating low-concentration $\mathrm{CNFs}$ can reduce porosity and increase density of the $\mathrm{CNF} /$ cement composites. When the content of CNFs was greater than $0.2 \%$ by weight of cement, the porosity otherwise increased negatively. Murugan et al. [162] also gave evidence that the effect of 2D reduced GO sheets on the optimization of the pores/ void structures of the cement matrix is superior to that of nano- $\mathrm{SiO}_{2}$. Du and Pang [163] found that incorporating the graphene nanoplatelet (GNP) in the mortar caused a reduction in the critical pore diameter by more than $30 \%$. The resistance of the cement mortar to water permeability, chloride diffusion, and chloride migration were improved with the incorporation of GNP than those of the cement composites modified by nano- $\mathrm{SiO}_{2}$ and nano- $\mathrm{TiO}_{2}$. Nanomaterials accelerating the cement hydration can lead to the earlier formation of denser microstructures of the cement-based material and those with pozzolanic activity can also compact the microstructures of the nanocomposites by consuming calcium hydroxide to produce more C-S-H $[111,113,136,164]$.

\section{Commercialization}

\subsection{Market}

Globally, various products such as nano- $\mathrm{CaCO}_{3}$, nanozinc oxide, and nano- $\mathrm{SiO}_{2}$ have possessed some market scale of nanomaterials. The nanomaterials, including nano-ceramic materials, nano-textile materials, and nano-modified coating materials, have been successfully developed and preliminarily industrialized. The application of nanomaterials in the field of medical diagnostic preparations and microelectronics is shifting from the 
lab investigations to commercialization. The global market scale of nanomaterials is constantly growing, which is attributed to the continuous innovation of nanotechnology, gradual improvement of manufacturing technology, continuous reduction of production cost of nanomaterials, and development of new application fields. The global and China market scales of nanomaterials in the past, present, and future are shown in Figures 18-20 [165].

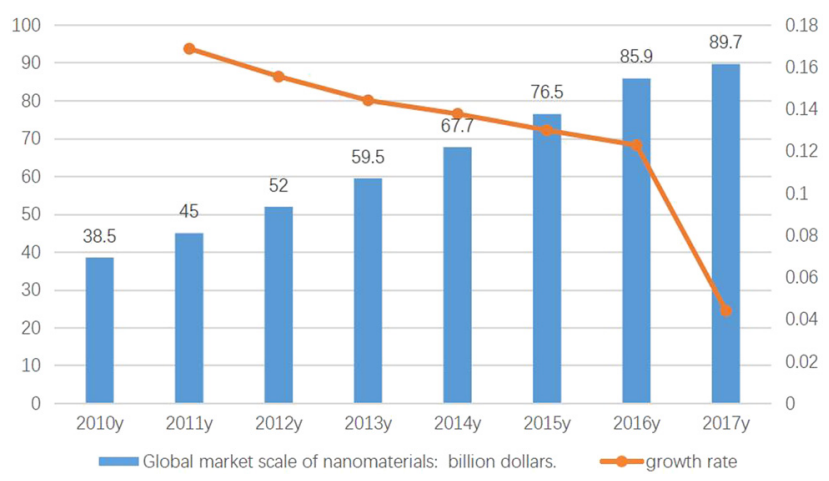

Figure 18: Global market scale of nanomaterials in 2010-2017 [165].

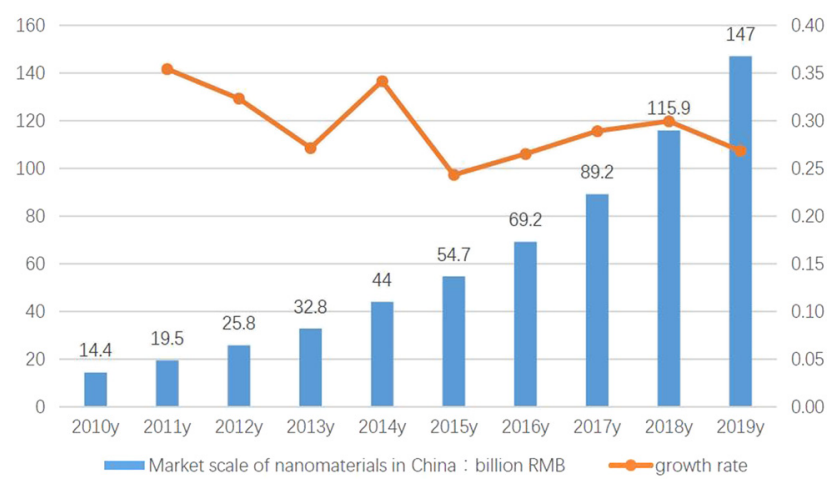

Figure 19: Market scale of nanomaterials in China in 2010-2019 [165].

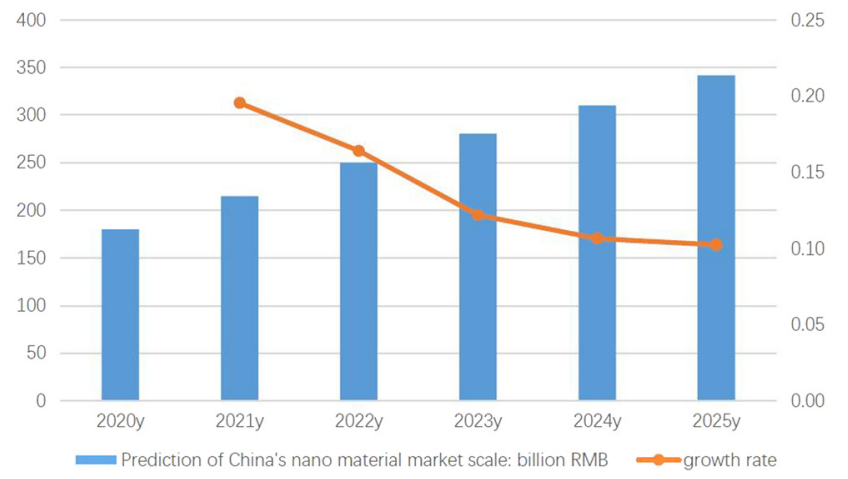

Figure 20: Prediction of China's nanomaterials market scale in 2020-2025 [165].
In recent years, China's nanomaterial manufacturing industry developed rapidly. Under the guidance of the national strategy, the application of nanomaterials and nanotechnology in energy, environment, resources, and water treatment industries has made a good start. With the continuous push of downstream demands for nanomaterials and the continuous innovation of nanotechnology, the market demands are still growing.

\subsection{Cost}

Currently, nanomaterials are usually expensive. Therefore, in civil engineering, nanomaterials could not be employed as the main reinforcing materials to improve various properties such as strength, toughness, and durability of concrete. Recently, we conducted comprehensive and systematic cracking resistance tests of face-slab concrete of a rock-fill dam. The various cracking resistance additives were adopted, among which the nanomaterial with a concentration of $0.1 \mathrm{wt}$ $\%$ was selected. The mix proportion of face-slab concrete modified by the nanomaterial is shown in Table 1. Based on this mix proportion, the increased costs per cubic meter of the concrete with the addition of different nanomaterials are presented in Table 2. The optimum concentrations of nanomaterials come from the literature $[127,149,166]$ and the prices of various nanomaterials are collected from the market price released by the nanomaterial manufacturers in China currently. It can be seen that the increased costs of per cubic meter of concretes with the addition of graphene and its derivatives, CNTs, and nano- $\mathrm{SiO}_{2}$ are greater than 100 RMB, which makes these nanomaterials unaffordable to be widely used in the civil engineering. Instead, nano$\mathrm{CaCO}_{3}$ and $\mathrm{CNFs}$ are the cheapest materials among these kinds of nanomaterials. Based on the calculation, the increased cost per cubic meter of concrete with the addition of nanomaterials such as nano- $\mathrm{CaCO}_{3}$ and $\mathrm{CNFs}$ is less than 100 RMB. Compared to the graphene, CNTs, and other nanomaterials, they have been applied in the field of construction to a certain extent. With the continuous expansion of the market scale of nanomaterials, the cost of nanomaterials will be further reduced. It is expected that in the next 5-10 years, with the operation of large-scale production line of nanomaterials, the cost increase in cement-based materials due to the incorporation of nanomaterials will be reduced to $10-15 \%$, and the mechanical properties of cement-based materials will be improved by more than $50 \%$ with the 
Table 1: Mix proportions of face-slab concrete of a rock-fill dam $\left(\mathrm{kg} / \mathrm{m}^{3}\right)$

\begin{tabular}{lllllllllll}
\hline Specimen group & w/b & Water & Cement & Fly ash & Sand & $\begin{array}{l}\text { Small } \\
\text { gravel }\end{array}$ & $\begin{array}{l}\text { Middle } \\
\text { gravel }\end{array}$ & $\begin{array}{l}\text { Water- } \\
\text { reducer } \\
\text { (WR) }\end{array}$ & $\begin{array}{l}\text { Air-entraining } \\
\text { agent (AE) }\end{array}$ & Nanomaterial \\
\hline Nano-concrete (NC) & 0.48 & 120 & 188 & 63 & 768 & 541 & 661 & 1.875 & 0.0088 & 0.25 \\
\hline
\end{tabular}

Table 2: Comparison of increased cost per cubic meter of different nanocomposites

\begin{tabular}{llll}
\hline Nanomaterials & Price & $\begin{array}{l}\text { Optimum dosage } \\
\text { (by weight of cement) }\end{array}$ & $\begin{array}{l}\text { Int\%) } \\
\text { cement-based } \text { materials w/b } \mathbf{~}=\mathbf{0 . 4 8}\left(\mathbf{R M B} / \mathbf{m}^{\mathbf{3}}\right)\end{array}$ \\
\hline Multilayer graphene & $6 \mathrm{RMB} / \mathrm{g}$ & 0.03 & 451.8 \\
Graphene oxide & $30 \mathrm{RMB} / \mathrm{g}$ & 0.03 & 2259 \\
Multiwalled carbon nanotubes & $1800 \mathrm{RMB} / \mathrm{kg}$ & 0.1 & 451.8 \\
Nano-calcium carbonate & $25 \mathrm{RMB} / \mathrm{kg}$ & 1.0 & 62.8 \\
Nano-silica & $60 \mathrm{RMB} / \mathrm{kg}$ & 3.0 & 451.8 \\
Carbon nanofiber & $270 \mathrm{RMB} / \mathrm{kg}$ & 0.1 & 67.8 \\
\hline
\end{tabular}

optimum dosage of nanomaterials. The nanomaterials will become one of the main reinforcing materials for the construction materials.

\subsection{Nano-modified cement-based material practices}

Gaia is one of the first commercial nano-admixtures used in concrete, which was developed by Ulmen S.A. and Cognoscible Technologies to substitute for silica fume at ready-mixed concrete facilities certified by the ISO 14001-Environmental Management System [167]. The product is in liquid form, which can effectively disperse nano- $\mathrm{SiO}_{2}$ particles in concrete. Gaia exhibits perfect effects of slump improving and water reducing for the concrete. The design of self-compacting concrete becomes a very easy task with the help of the Gaia. The application of Gaia with a concentration of $1.3 \mathrm{wt}$ $\%$ provided a slump loss of $30 \%$ in $1.5 \mathrm{~h}$ at an ambient temperature of $20{ }^{\circ} \mathrm{C}$ for concrete. Meanwhile, incorporation of Gaia provided almost a twofold increase in concrete compressive strength at $7 \mathrm{~d}$ and $28 \mathrm{~d}$ as well as about three times higher than the early compressive strength (at the age of $1 \mathrm{~d}$ ) of the reference concrete.

PCE, one of the nanomaterials, is usually taken as an admixture in concrete [168]. The constructions of spectacular concrete structures have benefited from the outstanding performance of current commercial PCE products such as the construction of the tallest skyscraper in the world - Burj Khalifa, with the height of $820 \mathrm{~m}$ in Dubai. The formulation of high strength concrete incorporating a kind of PCE product and a retarder enabled the structural concrete to pump up to a record height of $650 \mathrm{~m}$ and exhibited slump retention over $3 \mathrm{~h}$ at a temperature of $50{ }^{\circ} \mathrm{C}$ for the concrete [169]. The easy handling guideline or technique enables PCE to be one of the most popular nanomaterials adopted in cement-based materials.

\section{Conclusions and future challenges}

\subsection{Conclusions}

The science of cement-based materials is a multidisciplinary research area where nanotechnology potentially provides the chance to enhance the understanding of the cementitious composite behavior, to modify their properties, and to decrease manufacturing and ecological cost of materials for civil engineering. The basic properties of the nanomaterials utilized in cement-based materials, dispersion methods of nanomaterials, property enhancement of nano-modified cementitious composites, and the market, cost, and engineering practices of nanomaterials for cement-based materials were discussed in this study. The conclusions are drawn as follows:

(1) Nanomaterials utilized in cement-based materials possess high specific surface area, nano-level size, and pozzolanic activity, which in turn lead to the nucleation effect, filling effect, and bridging effect. Thus, nanomaterials with superior properties can 
engineer cement-based materials to improve their mechanical properties, durability, and sustainability.

(2) The property improvements of nanocomposites mainly exhibit in the following aspects: hydration acceleration and early strength improvement, optimization of the composition and morphology of hydration products, formation of dense microstructure and more efficient cement hydration, improved aggregate-paste bond strength, higher compressive strength, tensile strength, tougher cement-based materials, and improved durability such as permeability and corrosion resistance.

(3) The dispersity of nanomaterials is the decisive factor which affects the efficiency of property enhancement of cement-based composites. The common dispersion approaches include physical dispersion method, surfactant modification method, covalent functionalization method, cement admixtures modification method, electric field induction method, and so on.

(4) The market demand scale for nanomaterials is still growing worldwide. With the operation of largescale production line of nanomaterials, the costs of nanomaterials and the cementitious nanocomposites are expected to be largely reduced.

\subsection{Future challenges}

Further efforts devoting to the investigations and practices of nano-modified cement-based materials are listed below.

(1) Effective dispersion of nanomaterials is very important to achieve the full benefits of nanocomposites. Self-agglomeration, especially at high concentration of nanomaterials, usually results in nonhomogeneous microstructure development and inferior behavior of the nanocomposites. Therefore, it is necessary to further develop the dispersion technique in largescale field applications.

(2) Whether CNTs/CNFs can promote the hydration process of nanocomposites is not fully understood, further work should be conducted experimentally and theoretically. Incorporation of nanomaterials can improve the microstructure of cement-based composites, reduce their porosity, and reinforce permeability and corrosion resistance. However, few studies have been conducted on the freeze-thaw cycles and carbonation resistance and no consistent conclusions have been drawn in these aspects. Further in-depth studies are urgently required.
(3) The biggest challenge for utilizing nano-modified cement-based materials in civil engineering is the project cost. On one hand, we not only reduce the cost and improve the cost-effectiveness in the nanomaterial preparation but also study the mechanism and conduct tests to quantitatively characterize the optimization of performance of nanocomposites, in order to improve the material utilization efficiency.

Acknowledgments: This work was supported by grants from the National Natural Science Foundation of China (Grant no. 51879235, 51479178, and 51778582). Professor S. P. Shah is highly appreciated for his kind guidance and valuable suggestions to this work.

\section{References}

[1] Roco MC. The long view of nanotechnology development: the national nanotechnology initiative at 10 years. J Nanopart Res. 2011;13(2):427-45.

[2] Yildiz I. Applications of magnetic nanoparticles in biomedical separation and purification. Nanotechnol Rev. 2016;5(3):331-40.

[3] Jia F, Li G, Yang B, Yu B, Shen Y, Cong H. Investigation of rare earth upconversion fluorescent nanoparticles in biomedical field. Nanotechnol Rev. 2019;8(1):1-17.

[4] Liu Y, Ong CN, Xie J. Emerging nanotechnology for environmental applications. Nanotechnol Rev. 2016;5(1):1-2.

[5] Gannavarapu KP, Thakkar M, Veerapaga S, Wei L, Dandamudi RB, Mitra S. Novel diatom- $\mathrm{FeO}_{\mathrm{x}}$ composite as highly active catalyst in photodegradation of Rhodamine-6G. Nanotechnol Rev. 2018;7(3):247-55.

[6] Tans SJ, Verschueren AR, Dekker C. Room-temperature transistor based on a single carbon nanotube. Nature. 1998;393(6680):49-52.

[7] Zhang P, Li Q-F, Wang J, Shi Y, Ling Y-F. Effect of PVA fiber on durability of cementitious composite containing nano- $\mathrm{SiO}_{2}$. Nanotechnol Rev. 2019;8(1):116-127.

[8] Cumings J, Collins PG, Zettl A. Materials: peeling and sharpening multiwall nanotubes. Nature. 2000;406(6796):586.

[9] Kazemi M, Ghobadi M, Mirzaie A. Cobalt ferrite nanoparticles $\left(\mathrm{CoFe}_{2} \mathrm{O}_{4}\right.$ MNPs) as catalyst and support: magnetically recoverable nanocatalysts in organic synthesis. Nanotechnol Rev. 2018;7(1):43-68.

[10] Saini D. Synthesis and functionalization of graphene and application in electrochemical biosensing. Nanotechnol Rev. 2016;5(4):393-16.

[11] Power AC, Gorey B, Chandra S, Chapman J. Carbon nanomaterials and their application to electrochemical sensors: a review. Nanotechnol Rev. 2018;7(1):19-41. 
[12] Mohamed AR, Hansen W. Micromechanical modeling of crackaggregate interaction in concrete materials. Cem Concr Compos. 1999;21(5-6):349-59.

[13] Oh BH, Jang SY. Prediction of diffusivity of concrete based on simple analytic equations. Cem Concr Res. 2004;34(3):463-80.

[14] Wang X, Yang ZJ, Yates J, Jivkov A, Zhang C. Monte Carlo simulations of mesoscale fracture modelling of concrete with random aggregates and pores. Constr Build Mater. 2015;75:35-45.

[15] Scrivener KL, Nemati KM. The percolation of pore space in the cement paste/aggregate interfacial zone of concrete. Cem Concr Res. 1996;26(1):35-40.

[16] Breton D, Carles-Gibergues A, Ballivy G, Grandet J. Contribution to the formation mechanism of the transition zone between rock-cement paste. Cem Concr Res. 1993;23(2):335-46.

[17] Tang S, Li Z, Shao H, Chen E. Characterization of early-age hydration process of cement pastes based on impedance measurement. Constr Build Mater. 2014;68:491-500.

[18] Allen AJ, Thomas JJ, Jennings HM. Composition and density of nanoscale calcium-silicate-hydrate in cement. Nat Mater. 2007;6(4):311.

[19] Scrivener KL, Kirkpatrick RJ. Innovation in use and research on cementitious material. Cem Concr Res. 2008;38(2):128-136.

[20] Garboczi EJ, Bentz DP. Multiscale analytical/numerical theory of the diffusivity of concrete. Adv Cem Based Mater. 1998;8(2):77-88.

[21] Joachim C. To be nano or not to be nano? Nat Mater. 2005;4(2):107-109.

[22] Loeve S. About a definition of nano: how to articulate nano and technology. Hyle. 2010;16(1):3-18.

[23] Lövestam G, Rauscher H, Roebben G, Klüttgen BS, Gibson N, Putaud J-P, et al. Considerations on a definition of nanomaterial for regulatory purposes. Jt Res Cent (JRC) Ref Rep. 2010;80001-4.

[24] Valiev R. Materials science: nanomaterial advantage. Nature. 2002;419(6910):887-9.

[25] Hansen SF, Larsen BH, Olsen SI, Baun A. Categorization framework to aid hazard identification of nanomaterials. Nanotoxicology. 2007;1(3):243-50.

[26] Shahbazali E, Hessel V, Noël T, Wang Q. Metallic nanoparticles made in flow and their catalytic applications in organic synthesis. Nanotechnol Rev. 2014;3(1):65-86.

[27] Kreyling WG, Semmler-Behnke M, Chaudhry Q. A complementary definition of nanomaterial. Nano Today. 2010;5(3):165-8.

[28] Pan Z, He L, Qiu L, Korayem AH, Li G, Zhu JW, et al. Mechanical properties and microstructure of a graphene oxide-cement composite. Cem Concr Compos. 2015;58:140-7.

[29] Ajayan PM, Tour JM. Materials science: nanotube composites. Nature. 2007;447(7148):1066-8.

[30] Pan Z, Xie S, Chang B, Wang C, Lu L, Liu W, et al. Very long carbon nanotubes. Nature. 1998;394(6694):631-2.

[31] Novoselov KS, Geim AK, Morozov SV, Jiang D, Zhang Y, Dubonos SV, et al. Electric field effect in atomically thin carbon films. Science. 2004;306(5696):666-9.

[32] Lee C, Wei X, Kysar JW, Hone J. Measurement of the elastic properties and intrinsic strength of monolayer graphene. Science. 2008;321(5887):385-8.
[33] Kuilla T, Bhadra S, Yao D, Kim NH, Bose S, Lee JH. Recent advances in graphene based polymer composites. Prog Polym Sci. 2010;35(11):1350-75.

[34] Lambert TN, Chavez CA, Hernandez-Sanchez B, Lu P, Bell NS, Ambrosini A, et al. Synthesis and characterization of titania-graphene nanocomposites. J Phys Chem C. 2009;113(46):19812-23.

[35] Stankovich S, Dikin DA, Dommett GH, Kohlhaas KM, Zimney EJ, Stach EA, et al. Graphene-based composite materials. Nature. 2006;442(7100):282.

[36] Novoselov KS, Fal V, Colombo L, Gellert P, Schwab M, Kim K. A roadmap for graphene. Nature. 2012;490(7419):192-200.

[37] Huang X, Yin Z, Wu S, Qi X, He Q, Zhang Q, et al. Graphenebased materials: synthesis, characterization, properties, and applications. Small. 2011;7(14):1876-902.

[38] Horszczaruk E, Mijowska E, Kalenczuk RJ, Aleksandrzak M, Mijowska S. Nanocomposite of cement/graphene oxide impact on hydration kinetics and Young's modulus. Constr Build Mater. 2015;78:234-42.

[39] Kim KS, Zhao Y, Jang H, Lee SY, Kim JM, Kim KS, et al. Largescale pattern growth of graphene films for stretchable transparent electrodes. Nature. 2009;457(7230):706-10.

[40] Kosynkin DV, Higginbotham AL, Sinitskii A, Lomeda JR, Dimiev A, Price BK, et al. Longitudinal unzipping of carbon nanotubes to form graphene nanoribbons. Nature. 2009;458(7240):872-6.

[41] He Q, Deng H. Effect of graphene oxide size on cement-based composites. Bull Chin Ceram Soc. 2019;38(10):3145-9.

[42] Zheng M, Jagota A, Semke ED, Diner BA, McLean RS, Lustig SR, et al. DNA-assisted dispersion and separation of carbon nanotubes. Nat Mater. 2003;2(5):338-42.

[43] lijima S. Helical microtubules of graphitic carbon. Nature. 1991;354(6348):56-8.

[44] lijima S, Ichihashi T. Single-shell carbon nanotubes of 1-nm diameter. Nature. 1993;363(6430):603-5.

[45] Ruoff RS, Lorents DC. Mechanical and thermal properties of carbon nanotubes. Carbon. 1995;33(7):925-30.

[46] Peigney A, Laurent C, Flahaut E, Bacsa R, Rousset A. Specific surface area of carbon nanotubes and bundles of carbon nanotubes. Carbon. 2001;39(4):507-14.

[47] Salvetat J-P, Bonard J-M, Thomson N, Kulik A, Forro L, Benoit $W$, et al. Mechanical properties of carbon nanotubes. Appl Phys A. 1999;69(3):255-60.

[48] Belytschko T, Xiao S, Schatz GC, Ruoff R. Atomistic simulations of nanotube fracture. Phys Rev B. 2002;65(23):235430.

[49] Konsta-Gdoutos MS, Metaxa ZS, Shah SP. Highly dispersed carbon nanotube reinforced cement based materials. Cem Concr Res. 2010;40(7):1052-59.

[50] Shi T, Li Z, Guo J, Gong H, Gu C. Research progress on CNTs/ CNFs-modified cement-based composites - a review. Constr Build Mater. 2019;202:290-307.

[51] Yudasaka M, Komatsu T, Ichihashi T, lijima S. Singlewall carbon nanotube formation by laser ablation using double-targets of carbon and metal. Chem Phys Lett. 1997;278(1-3):102-6.

[52] Cheng H, Li F, Sun X, Brown S, Pimenta M, Marucci A, et al. Bulk morphology and diameter distribution of single-walled carbon nanotubes synthesized by catalytic decomposition of hydrocarbons. Chem Phys Lett. 1998;289(5-6):602-10. 
[53] Zhang D, Shi L, Fang J, Li X, Dai K. Preparation and modification of carbon nanotubes. Mater Lett. 2005;59(29-30):4044-47.

[54] Prasek J, Drbohlavova J, Chomoucka J, Hubalek J, Jasek 0, Adam V, et al. Methods for carbon nanotubes synthesis. J Mater Chem. 2011;21(40):15872-84.

[55] Ebbesen T, Ajayan P. Large-scale synthesis of carbon nanotubes. Nature. 1992;358(6383):220-2.

[56] Vilaplana J, Baeza F, Galao O, Zornoza E, Garcés P. Selfsensing properties of alkali activated blast furnace slag (BFS) composites reinforced with carbon fibers. Materials. 2013;6(10):4776-86.

[57] Endo M, Kim Y, Hayashi T, Nishimura K, Matusita T, Miyashita K, et al. Vapor-grown carbon fibers (VGCFs): basic properties and their battery applications. Carbon. 2001;39(9):1287-97.

[58] Zheng J-S, Zhang X-S, Li P, Zhou X-G, Yuan W-K. Microstructure effect of carbon nanofiber on electrocatalytic oxygen reduction reaction. Catal Today. 2008;131(1-4):270-7.

[59] Terrones H, Hayashi T, Munoz-Navia M, Terrones M, Kim Y, Grobert N, et al. Graphitic cones in palladium catalysed carbon nanofibres. Chem Phys Lett. 2001;343(3-4):241-50.

[60] Zheng R, Zhao Y, Liu H, Liang C, Cheng G. Preparation, characterization and growth mechanism of platelet carbon nanofibers. Carbon. 2006;44(4):742-6.

[61] Zhang J, Han B, Zhou NL, Fang J, Wu J, Ma ZM, et al. Preparation and characterization of nano/microcalcium carbonate particles/polypropylene composites. Prog Polym Sci. 2011;119(6):3560-65.

[62] Shaoyin W, Ensheng L. Characteristics of nano calcium Carbonate and Its Application. China Rubber Ind. 1999;46(3):146-51.

[63] Boyjoo Y, Pareek VK, Liu J. Synthesis of micro and nano-sized calcium carbonate particles and their applications. J Mater Chem A. 2014;2(35):14270-88.

[64] Land G, Stephan D. The influence of nano-silica on the hydration of ordinary Portland cement. J Mater Sci. 2012;47(2):1011-7.

[65] Dorcheh AS, Abbasi M. Silica aerogel; synthesis, properties and characterization. J Mater Process Technol. 2008;199(1-3):10-26.

[66] Senff L, Labrincha JA, Ferreira VM, Hotza D, Repette WL. Effect of nano-silica on rheology and fresh properties of cement pastes and mortars. Constr Build Mater. 2009;23(7):2487-491.

[67] Madani H, Bagheri A, Parhizkar T. The pozzolanic reactivity of monodispersed nanosilica hydrosols and their influence on the hydration characteristics of Portland cement. Cem Concr Res. 2012;42(12):1563-570.

[68] Nozawa K, Gailhanou H, Raison L, Panizza P, Ushiki H, Sellier E, et al. Smart control of monodisperse Stöber silica particles: effect of reactant addition rate on growth process. Langmuir. 2005;21(4):1516-23.

[69] Land G, Stephan D. Controlling cement hydration with nanoparticles. Cem Concr Compos. 2015;57:64-7.

[70] Alizadeh R, Raki L, Makar JM, Beaudoin JJ, Moudrakovski I. Hydration of tricalcium silicate in the presence of synthetic calcium-silicate-hydrate. J Mater Chem.

2009;19(42):7937-46.
[71] Thomas JJ, Jennings HM, Chen JJ. Influence of nucleation seeding on the hydration mechanisms of tricalcium silicate and cement. J Phys Chem C. 2009;113(11):4327-34.

[72] Ludwig H, Dressel D. Synthetische calcium-silikat-hydrate in fertigteilbetonen. BWI. 2011;5:46-50.

[73] Kong D, Du X, Wei S, Zhang H, Yang Y, Shah SP. Influence of nano-silica agglomeration on microstructure and properties of the hardened cement-based materials. Constr Build Mater. 2012;37:707-15.

[74] Kong D, Su Y, Du X, Yang Y, Wei S, Shah SP. Influence of nanosilica agglomeration on fresh properties of cement pastes. Constr Build Mater. 2013;43:557-62.

[75] Brown L, Sanchez F. Influence of carbon nanofiber clustering on the chemo-mechanical behavior of cement pastes. Cem Concr Compos. 2016;65:101-9.

[76] Shang Y, Zhang D, Yang C, Liu Y, Liu Y. Effect of graphene oxide on the rheological properties of cement pastes. Constr Build Mater. 2015;96:20-28.

[77] Szleifer I, Yerushalmi-Rozen R. Polymers and carbon nanotubes - dimensionality, interactions and nanotechnology. Polymer. 2005;46(19):7803-18.

[78] Strano MS, Moore VC, Miller MK, Allen MJ, Haroz EH, Kittrell C, et al. The role of surfactant adsorption during ultrasonication in the dispersion of single-walled carbon nanotubes. J Nanosci Nanotechnol. 2003;3(1-2):81-6.

[79] Metaxa ZS, Konsta-Gdoutos MS, Shah SP. Carbon nanofiber cementitious composites: effect of debulking procedure on dispersion and reinforcing efficiency. Cem Concr Compos. 2013;36:25-32.

[80] Sandler J, Shaffer M, Prasse T, Bauhofer W, Schulte K, Windle A. Development of a dispersion process for carbon nanotubes in an epoxy matrix and the resulting electrical properties. Polymer. 1999;40(21):5967-71.

[81] Qi G-Q, Cao J, Bao R-Y, Liu Z-Y, Yang W, Xie B-H, et al. Tuning the structure of graphene oxide and the properties of poly (vinyl alcohol)/graphene oxide nanocomposites by ultrasonication. J Mater Chem A. 2013;1(9):3163-70.

[82] Mendoza O, Sierra G, Tobón JI. Influence of super plasticizer and $\mathrm{Ca}(\mathrm{OH})_{2}$ on the stability of functionalized multi-walled carbon nanotubes dispersions for cement composites applications. Constr Build Mater. 2013;47:771-8.

[83] Delozier D, Tigelaar D, Watson K, Smith Jr, J, Klein D, Lillehei $P$, et al. Investigation of ionomers as dispersants for single wall carbon nanotubes. Polymer. 2005;46(8):2506-21.

[84] Islam MF, Rojas E, Bergey D, Johnson A, Yodh A. High weight fraction surfactant solubilization of single-wall carbon nanotubes in water. Nano Lett. 2003;3(2):269-73.

[85] Moore VC, Strano MS, Haroz EH, Hauge RH, Smalley RE, Schmidt J, et al. Individually suspended single-walled carbon nanotubes in various surfactants. Nano Lett. 2003;3(10):1379-82.

[86] O’Connell MJ, Boul P, Ericson LM, Huffman C, Wang Y, Haroz E, et al. Reversible water-solubilization of single-walled carbon nanotubes by polymer wrapping. Chem Phys Lett. 2001;342(3-4):265-71.

[87] Davis VA, Ericson LM, Parra-Vasquez ANG, Fan H, Wang Y, Prieto V, et al. Phase behavior and rheology of SWNTs in superacids. Macromolecules. 2004;37(1):154-60.

[88] Hui CL, Li XG, Hsing IM. Well-dispersed surfactant-stabilized $\mathrm{Pt} / \mathrm{C}$ nanocatalysts for fuel cell application: Dispersion 
control and surfactant removal. Electrochim Acta. 2005;51(4):711-9.

[89] Xiong M, Wu L, Zhou S, You B. Preparation and characterization of acrylic latex/nano-SiO ${ }_{2}$ composites. Polym Int. 2002;51(8):693-8.

[90] Ma X-K, Lee N-H, Oh H-J, Kim J-W, Rhee C-K, Park K-S, et al. Surface modification and characterization of highly dispersed silica nanoparticles by a cationic surfactant. Colloids Surf A Physicochem Eng Asp. 2010;358(1-3):172-6.

[91] Wallace EJ, Sansom MS. Carbon nanotube self-assembly with lipids and detergent: a molecular dynamics study. Nanotechnology. 2008;20(4):045101.

[92] Ma P-C, Siddiqui NA, Marom G, Kim J-K. Dispersion and functionalization of carbon nanotubes for polymer-based nanocomposites: a review. Compos Part A: Appl Sci Manuf. 2010;41(10):1345-67.

[93] Chen H, Zhou S, Gu G, Wu L. Modification and dispersion of nanosilica. J Dispers Sci \& Technol. 2005;25(6):837-48.

[94] Gu Y, Ran Q, Shu X, Yu C, Chang H, Liu J. Synthesis of nanoSiO ${ }_{2} @$ PCE core-shell nanoparticles and its effect on cement hydration at early age. Constr Build Mater. 2016;114:673-80.

[95] Chen Z, Lim JLG, Yang E-H. Ultra high performance cementbased composites incorporating low dosage of plasma synthesized carbon nanotubes. Mater \& Des. 2016;108:479-87.

[96] Li G, Yue J, Guo CH, Ji YS. Influences of modified nanoparticles on hydrophobicity of concrete with organic film coating. Constr Build Mater. 2018;169:1-7.

[97] Saez de Ibarra Y, Gaitero J, Erkizia E, Campillo I. Atomic force microscopy and nanoindentation of cement pastes with nanotube dispersions. Phys Status Solidi (a). 2006;203(6):1076-1081.

[98] Shama P, Sohel R, Raul F. A review on nanomaterial dispersion, microstructure, and mechanical properties of carbon nanotube and nanofiber reinforced cementitious composites. J Nanomaterials. 2013;4:1-19.

[99] Yazdanbakhsh A, Grasley Z, Tyson B, Al-Rub RA. Carbon nano filaments in cementitious materials: some issues on dispersion and interfacial bond. Spec Publ. 2009;267:21-34.

[100] Li GY, Wang PM, Zhao X. Mechanical behavior and microstructure of cement composites incorporating surfacetreated multi-walled carbon nanotubes. Carbon. 2005;43(6):1239-45.

[101] Li GY, Wang PM, Zhao X. Pressure-sensitive properties and microstructure of carbon nanotube reinforced cement composites. Cem Concr Compos. 2007;29(5):377-82.

[102] Martin C, Sandler J, Windle A, Schwarz M-K, Bauhofer W, Schulte $\mathrm{K}$, et al. Electric field-induced aligned multi-wall carbon nanotube networks in epoxy composites. Polymer. 2005;46(3):877-86.

[103] Bullard JW, Jennings HM, Livingston RA, Nonat A, Scherer GW, Schweitzer JS, et al. Mechanisms of cement hydration. Cem Concr Res. 2011;41(12):1208-23.

[104] Lin F, Meyer C. Hydration kinetics modeling of Portland cement considering the effects of curing temperature and applied pressure. Cem Concr Res. 2009;39(4):255-65.

[105] Nicoleau L, Gädt T, Chitu L, Maier G, Paris O. Oriented aggregation of calcium silicate hydrate platelets by the use of comb-like copolymers. Soft Matter. 2013;9(19):4864-74.
[106] Sanchez F, Sobolev K. Nanotechnology in concrete - a review. Constr Build Mater. 2010;24(11):2060-71.

[107] Silvestre J, Silvestre N, De Brito J. Review on concrete nanotechnology. Eur J Environ Civ Eng. 2016;20(4):455-85.

[108] Björnström J, Martinelli A, Matic A, Börjesson L, Panas I. Accelerating effects of colloidal nano-silica for beneficial calcium-silicate-hydrate formation in cement. Chem Phys Lett. 2004;392(1-3):242-8.

[109] Qing Y, Zenan Z, Deyu K, Rongshen C. Influence of nano-SiO addition on properties of hardened cement paste as compared with silica fume. Constr Build Mater. 2007;21(3):539-45.

[110] Lin D, Lin K, Chang W, Luo H, Cai M. Improvements of nano$\mathrm{SiO}_{2}$ on sludge/fly ash mortar. Waste Manag. 2008;28(6):1081-7.

[111] Kong D, Corr DJ, Hou P, Yang Y, Shah SP. Influence of colloidal silica sol on fresh properties of cement paste as compared to nano-silica powder with agglomerates in micron-scale. Cem Concr Compos. 2015;63:30-41.

[112] Wang L, Zheng D, Zhang S, Cui H, Li D. Effect of nano-SiO ${ }_{2}$ on the hydration and microstructure of Portland cement. Nanomaterials. 2016;6(12):241.

[113] Abu-Lebdeh T, Petrescu V, Victoria R, Al-Nasra M, Petrescu T, Ion $\mathrm{F}$. Effect of nano silica $\left(\mathrm{SiO}_{2}\right)$ on the hydration kinetics of cement. Eng Rev. 2019;39(3):248-60.

[114] Sato T, Beaudoin JJ. The effect of Nano-sized $\mathrm{CaCO} 3$ addition on the hydration of OPC containing high volumes of ground granulated blast-furnace slag. Paper presented at: The 2nd International Symposium Advanced Concrete Science Engineering. Quebec City, Canada. 2006.

[115] Sato T, Diallo F. Seeding effect of nano- $\mathrm{CaCO}_{3}$ on the hydration of tricalcium silicate. Trans Res Rec. 2010;2141(1):61-7.

[116] Qian KL, Meng T, Qian XQ, Zhan SL. Research on some properties of fly ash concrete with nano- $\mathrm{CaCO}_{3}$ middle slurry. Key Eng Mater. 2009;405-406:186-90.

[117] Liu X, Chen L, Liu A, Wang X. Effect of nano- $\mathrm{CaCO}_{3}$ on properties of cement paste. Energy Procedia. 2012;16:991-6.

[118] Camiletti J, Soliman AM, Nehdi ML. Effect of nano-calcium carbonate on early-age properties of ultra-high-performance concrete. Mag Concr Res. 2013;65(5):297-307.

[119] Meng T, Yu Y, Wang Z. Effect of nano- $\mathrm{CaCO}_{3}$ slurry on the mechanical properties and micro-structure of concrete with and without fly ash. Compos Part B: Eng. 2017;117:124-9.

[120] Yang H, Che Y, Leng F. High volume fly ash mortar containing nano-calcium carbonate as a sustainable cementitious material: microstructure and strength development. Sci Rep. 2018;8(1):16439.

[121] Scheetz B, Tikalsky P, Badger S. Control of the microstructure of concrete: a case for nanometer-sized seeding. Paper presented at: Proceedings of the 11th International Congress on the Chemsitry of Cement, G. Grieveand, G. Owens, editors. Durban, South Africa. 2003.

[122] Nicoleau L. New calcium silicate hydrate network. Trans Res Rec. 2010;2142(1):42-51.

[123] Long G, Li Y, Ma C, Xie Y, Shi Y. Hydration kinetics of cement incorporating different nanoparticles at elevated temperatures. Thermochim Acta. 2018;664:108-17. 
[124] Makar J, Margeson J, Luh J. Carbon nanotube/cement composites -early results and potential applications. Proceedings of the 3rd International Conference on Construction Materials: Performance, Innovations and Structural Implications. Canada: Vancouver. 2005; pp. 1-10.

[125] Makar JM, Chan GW. Growth of cement hydration products on single-walled carbon nanotubes. J Am Ceram Soc. 2009;92(6):1303-10.

[126] Cui H, Yang S, Memon S. Development of carbon nanotube modified cement paste with microencapsulated phasechange material for structural-functional integrated application. Int J Mol Sci. 2015;16(4):8027-39.

[127] Zhao J, Ren S, Du Y, Zhu W, Wang W, Kong L, et al. Study on the influence of carbon nanotubes on the mechanical properties of portland cement. Bull Chin Ceram Soc. 2013;32(7):1361-6.

[128] Amin M, El-Gamal S, Hashem F. Fire resistance and mechanical properties of carbon nanotubes-clay bricks wastes (Homra) composites cement. Constr Build Mater. 2015;98:237-49.

[129] Shi T, Gao Y, Corr DJ, Shah SP. FTIR study on early-age hydration of carbon nanotubes-modified cement-based materials. Adv Cem Res. 2018;1-40.

[130] Gaitero JJ, Campillo I, Guerrero A. Reduction of the calcium leaching rate of cement paste by addition of silica nanoparticles. Cem Concr Res. 2008;38(8-9):1112-8.

[131] Collepardi S, Borsoi A, Olagot JO, Troli R, Collepardi M, Curzio A. Influence of nano-sized mineral additions on performance of SCC. Paper presented at: Applications of Nanotechnology in Concrete Design: Proceedings of the International Conference held at the University of Dundee, Scotland, UK on 7 July 2005; 2005.

[132] Bauer BJ, Liu DW, Jackson CL, Barnes JD. Epoxy/SiO interpenetrating polymer networks. Polym Adv Technol. 1996;7(4):333-9.

[133] Jo B-W, Kim C-H, Tae G-H, Park J-B. Characteristics of cement mortar with nano- $\mathrm{SiO}_{2}$ particles. Constr Build Mater. 2007;21(6):1351-55.

[134] Choolaei M, Rashidi AM, Ardjmand M, Yadegari A, Soltanian $\mathrm{H}$. The effect of nanosilica on the physical properties of oil well cement. Mater Sci Engineering: A. 2012;538:288-94.

[135] Hou P, Kawashima S, Kong D, Corr DJ, Qian J, Shah SP. Modification effects of colloidal nanoSiO $\mathrm{S}_{2}$ on cement hydration and its gel property. Compos Part B: Eng. 2013;45(1):440-8.

[136] Li G. Properties of high-volume fly ash concrete incorporating nano- $\mathrm{SiO}_{2}$. Cem Concr Res. 2004;34(6):1043-9.

[137] Givi AN, Rashid SA, Aziz FNA, Salleh MAM. Experimental investigation of the size effects of $\mathrm{SiO}_{2}$ nano-particles on the mechanical properties of binary blended concrete. Compos Part B: Eng. 2010;41(8):673-7.

[138] Pourjavadi A, Fakoorpoor SM, Khaloo A, Hosseini P. Improving the performance of cement-based composites containing superabsorbent polymers by utilization of nano- $\mathrm{SiO}_{2}$ particles. Mater \& Des. 2012;42:94-101.

[139] Garg R, Bansal M, Aggarwal Y. Strength, rapid chloride penetration and microstructure study of cement mortar incorporating micro and nano silica. Int J Electrochem Sci. 2016;11:3697-713.

[140] Nazerigivi A, Najigivi A. Study on mechanical properties of ternary blended concrete containing two different sizes of nano-SiO2. Compos Part B: Eng. 2019;167:20-4.

[141] Lu S-N, Xie N, Feng L-C, Zhong J. Applications of nanostructured carbon materials in constructions: The state of the art. J Nanomaterials. 2015;4:1-10.

[142] Sobolkina A, Mechtcherine V, Khavrus V, Maier D, Mende M, Ritschel M, Leonhardt A. Dispersion of carbon nanotubes and its influence on the mechanical properties of the cement matrix. Cem Concr Compos. 2012;34(10):1104-13.

[143] Wang B, Han Y, Pan B, Zhang T. Mechanical and morphological properties of highly dispersed carbon nanotubes reinforced cement based materials. J Wuhan Univ Technol Mater Sci Ed. 2013;28(1):82-7.

[144] Konsta-Gdoutos MS, Metaxa ZS, Shah SP. Multi-scale mechanical and fracture characteristics and early-age strain capacity of high performance carbon nanotube/cement nanocomposites. Cem Concr Compos. 2010;32(2):110-5.

[145] Xu S, Liu J, Li Q. Mechanical properties and microstructure of multi-walled carbon nanotube-reinforced cement paste. Constr Build Mater. 2015;76:16-23.

[146] Metaxa ZS, Konsta-Gdoutos MS, Shah SP. Carbon nanofiber-reinforced cement-based materials. Transportation Res Rec. 2010;2142(1):114-8.

[147] Galao 0, Zornoza E, Baeza FJ, Bernabeu A, Garcés P. Effect of carbon nanofiber addition in the mechanical properties and durability of cementitious materials. Mater Construcc (Materiales de Construcción). 2012;307:343-57.

[148] S-H LV. Study on reinforcing and toughening of graphene oxide to cement-based composites. J Funct Mater. 2013;44(15):2227-31.

[149] S-H LV. Toughening effect and mechanism of graphene oxide nanosheets on cement matrix composites. Acta Materiae Compositae Sin. 2014;31(3):644-52.

[150] Shah SP, Konsta-Gdoutos MS, Metaxa Z, Mondal P. Nanoscale modification of cementitious materials, Nanotechnology in Construction 3. Springer; 2009; 125-30.

[151] Konsta-Gdoutos MS, Batis G, Danoglidis PA, Zacharopoulou AK, Zacharopoulou EK, Falara MG, et al. Effect of CNT and CNF loading and count on the corrosion resistance, conductivity and mechanical properties of nanomodified OPC mortars. Constr Build Mater. 2017;147:48-57.

[152] Danoglidis PA, Konsta-Gdoutos MS, Gdoutos EE, Shah SP. Strength, energy absorption capability and self-sensing properties of multifunctional carbon nanotube reinforced mortars. Constr Build Mater. 2016;120:265-74.

[153] Konsta-Gdoutos MS, Danoglidis PA, Falara MG, Nitodas SF. Fresh and mechanical properties, and strain sensing of nanomodified cement mortars: The effects of MWCNT aspect ratio, density and functionalization. Cem Concr Compos. 2017;82:137-51.

[154] Konsta-Gdoutos MS, Danoglidis PA, Shah SP. High modulus concrete: effects of low carbon nanotube and nanofiber additions. Theor Appl Fract Mech. 2019;103:102295.

[155] Mehta PK, Monteiro PJ. Concrete: Microstructure, Properties, and Materials; 2006; McGrawHill.

[156] Chaipanich A, Nochaiya T, Wongkeo W, Torkittikul P. Compressive strength and microstructure of carbon nano- 
tubes-fly ash cement composites. Mater Sci Engineering: A. 2010;527(4-5):1063-67.

[157] Zdravkov BD, Čermák JJ, Šefara M, Janků J. Pore classification in the characterization of porous materials: A perspective. Cent Eur J Chem. 2007;5(2):385-95.

[158] Zhang $\mathrm{M}-\mathrm{H}$, Li H. Pore structure and chloride permeability of concrete containing nano-particles for pavement. Constr Build Mater. 2011;25(2):608-16.

[159] Li G, Zhou JC, Yue J, Gao X, Wang KJ. Effects of nano-SiO ${ }_{2}$ and secondary water curing on the carbonation and chloride resistance of autoclaved concrete. Constr Build Mater. 2020;235:1-10.

[160] Wang B-M, Zhang Y. Synthesis and properties of carbon nanofibers filled cement-based composites combined with new surfactant methylcellulose. Mater Express. 2014;4(2):177-82.

[161] Wang BM, Zhang Y, Liu S. Influence of carbon nanofibers on the mechanical performance and microstructure of cement-based materials. Nanosci Nanotechnol Lett. 2013;5(10):1112-8.

[162] Murugan M, Santhanam M, Gupta SS, Pradeep T, Shah SP. Influence of 2D rGO nanosheets on the properties of OPC paste. Cem Concr Compos. 2016;70:48-59.
[163] Du H, Pang SD. Enhancement of barrier properties of cement mortar with graphene nanoplatelet. Cem Concr Res. 2015;76:10-19.

[164] Yang X, Liu J, Li H, Xu L, Ren Q, Li L. Effect of triethanolamine hydrochloride on the performance of cement paste. Constr Build Mater. 2019;200:218-25.

[165] Chinabaogao.com. China nanomaterials industry analysis report-market monitoring and development strategy planning, 2019, 2019-01-18.

[166] Han B, Sun S, Ding S, Zhang L, Yu X, Ou J. Review of nanocarbon-engineered multifunctional cementitious composites. Compos Pt A Appl Sci Manuf Compos Part A Appl Sci Manuf. 2015;70:69-81.

[167] Sobolev K, Gutierrez MF. How nanotechnology can change the concrete world. Am Ceram Soc Bull. 2005;84(11):16-9.

[168] Norhasri MSM, Hamidah MS, Fadzil AM. Applications of using nano material in concrete: a review. Constr Build Mater. 2017;133:91-7.

[169] Plank J, Sakai E, Miao CW, Yu C, Hong JX. Chemical admixturesChemistry, applications and their impact on concrete microstructure and durability. Cem Concr Res. 2015;78:81-9. 